\title{
Considerations for Application of Additive Manufacturing to Nuclear Reactor Core Components
}

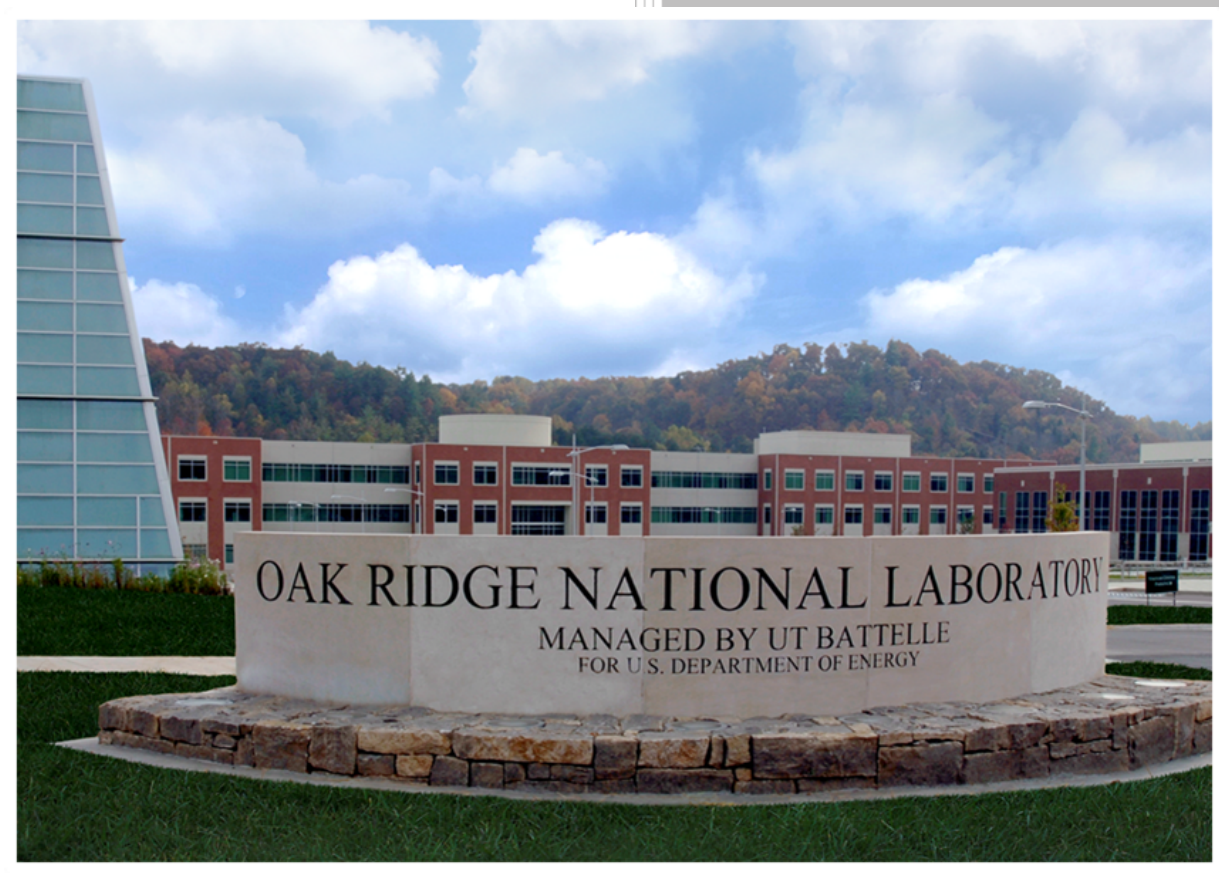

Approved for public release. Distribution is unlimited. 


\section{DOCUMENT AVAILABILITY}

Reports produced after January 1, 1996, are generally available free via US Department of Energy (DOE) SciTech Connect.

Website www.osti.gov

Reports produced before January 1, 1996, may be purchased by members of the public from the following source:

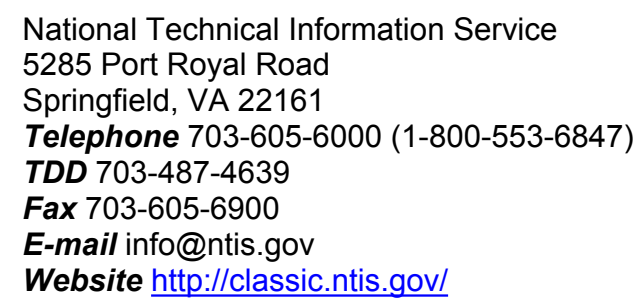

Reports are available to DOE employees, DOE contractors, Energy Technology Data Exchange representatives, and International Nuclear Information System representatives from the following source:

Office of Scientific and Technical Information

PO Box 62

Oak Ridge, TN 37831

Telephone 865-576-8401

Fax 865-576-5728

E-mail reports@osti.gov

Website http://www.osti.gov/contact.html

This report was prepared as an account of work sponsored by an agency of the United States Government. Neither the United States Government nor any agency thereof, nor any of their employees, makes any warranty, express or implied, or assumes any legal liability or responsibility for the accuracy, completeness, or usefulness of any information, apparatus, product, or process disclosed, or represents that its use would not infringe privately owned rights. Reference herein to any specific commercial product, process, or service by trade name, trademark, manufacturer, or otherwise, does not necessarily constitute or imply its endorsement, recommendation, or favoring by the United States Government or any agency thereof. The views and opinions of authors expressed herein do not necessarily state or reflect those of the United States Government or any agency thereof. 
MANUFACTURING DEMONSTRATION FACILITY

Materials Science and Technology Division

\title{
CONSIDERATIONS FOR APPLICATION OF ADDITIVE MANUFACTURING TO NUCLEAR REACTOR CORE COMPONENTS
}

\author{
Joseph Simpson \\ James Haley \\ Corson Cramer \\ Olivia Shafer \\ Amy Elliott \\ Bill Peter \\ Lonnie Love \\ Ryan Dehoff
}

Date Published:

May 31, 2019

Prepared by

OAK RIDGE NATIONAL LABORATORY

Oak Ridge, TN 37831-6283

managed by

UT-BATTELLE, LLC

for the

US DEPARTMENT OF ENERGY

under contract DE-AC05-00OR22725 



\section{CONTENTS}

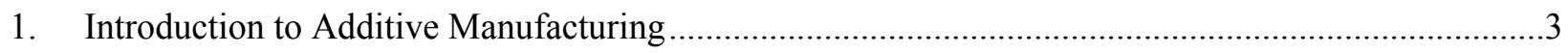

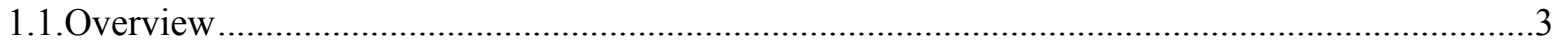

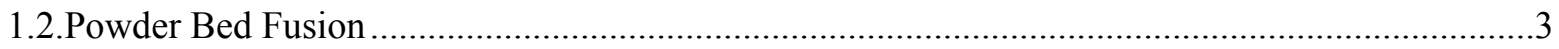

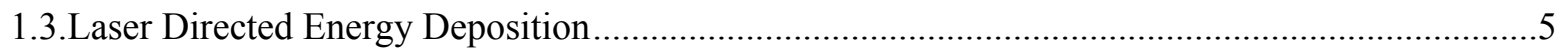

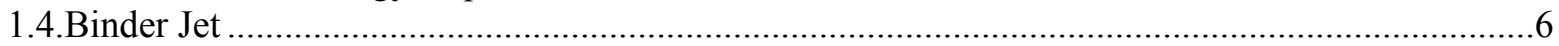

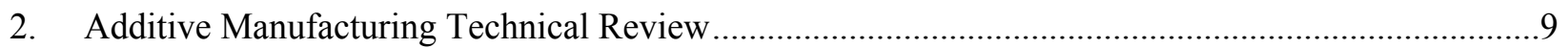

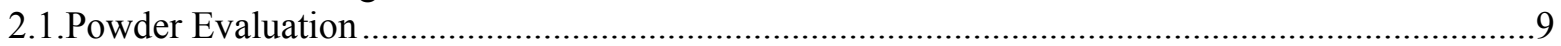

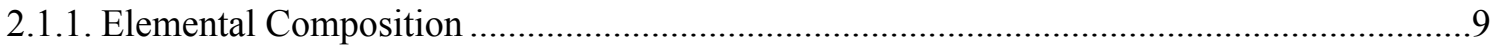

2.1.1.Powder Flowability, Geometry, and Size ...................................................................

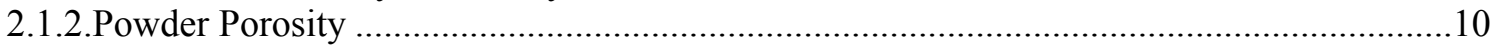

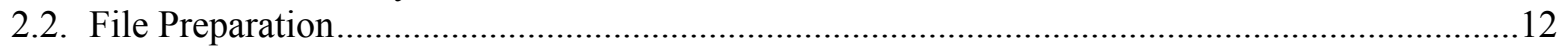

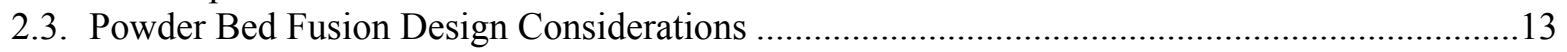

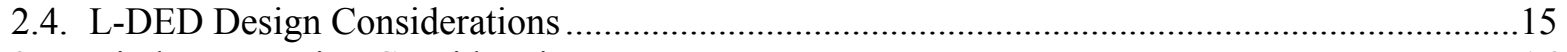

2.5. Binder Jet Design Considerations.................................................................................16

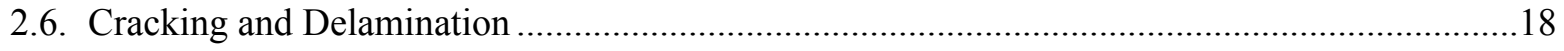

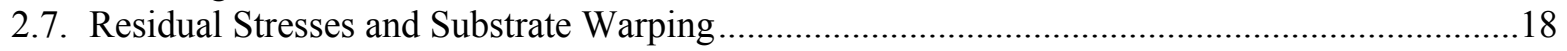

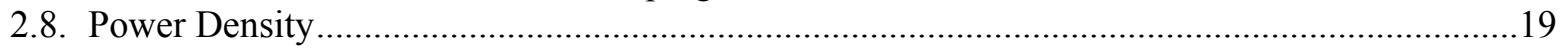

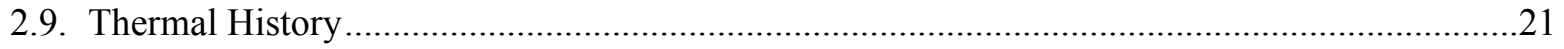

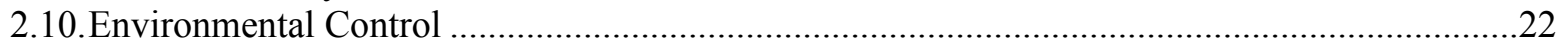

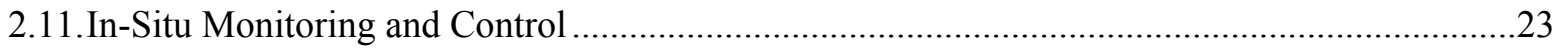

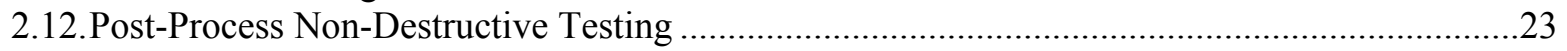

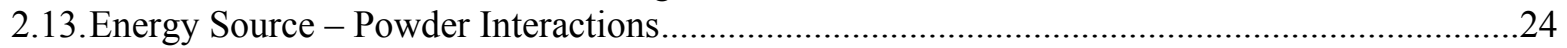

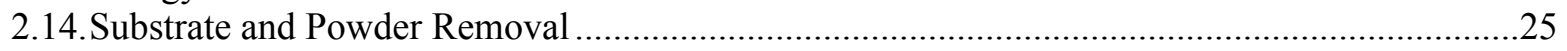

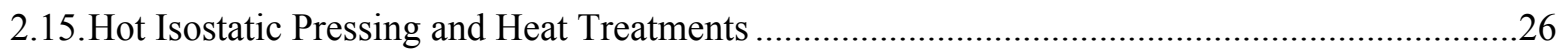

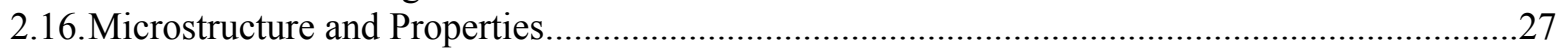

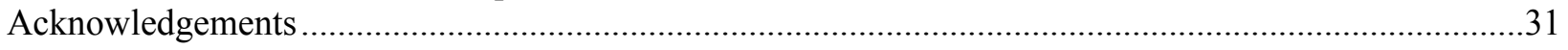

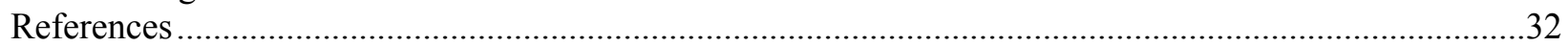




\section{INTRODUCTION TO ADDITIVE MANUFACTURING}

Multiple additive manufacturing (AM) technologies have been developed in recent years and are posed to fundamentally alter the way in which components are designed and manufactured. Key AM technologies of deemed relevant to nuclear reactor core structures are selective laser melting (SLM), electron beam melting (EBM), laser directed energy deposition (L-DED), and binder jetting. These technologies are not currently in wide-spread use in the fabrication of components for nuclear power plant (NPP) service, but have the potential to drastically reduce fabrication costs and timelines, combine multiple systems and assembled components into single parts, and increase safety and performance by tailoring local material properties and redesigning geometries for optimal load paths.

Additive manufacturing is a collection of technologies that fabricate components by selectively adding material layer-by-layer as opposed to conventional subtractive manufacturing, which removes material from a blank or billet or shapes material via stamping or forging. AM has progressed rapidly in the last 30 years from rapid design prototyping with polymers in the automotive industry to scale production of metal components as evidenced by Boeing's use of additive manufacturing to reduce weight in the 787 Dreamliner [1] and SES-15 spacecraft [2] and General Electric's decision to produce aviation fuel injection nozzles via additive manufacturing [3]. Some of the most common metal AM technologies at the time of this review are SLM and EBM (both of which are powder bed fusion (PBF) technologies [4]-[6]), L-DED, and binder jetting.

\subsection{OVERVIEW}

The following chapter represents the current state of literature on the selected additive manufacturing technologies and was written with an emphasis on quality control and material performance repeatability. Research and standards published by government entities such as the National Institute of Standards and Technology (NIST) and Department of Energy (DOE) have been included where applicable. It is recommended that literature be reviewed, and new knowledge integrated no less frequently than every four years due to the rapid pace of advancements in additive manufacturing and associated industries. AM presents unique challenges in certification for NPP applications such as anisotropic material properties, porosity, underdeveloped process control feedback systems, and reproducibility. This chapter begins with an overview of the selected AM technologies, followed by a systematic review of literature to detail the fabrication process and difficulties with repeatably fabricating fully dense, geometrically accurate components with known material properties.

\subsection{POWDER BED FUSION}

Powder bed fusion sequentially melts multiple thin metal powder layers together with a focused energy source to progressively build a component layer by layer. A three-dimensional computer aided design (CAD) file of a component is first "sliced" into thin planar layers as depicted in Figure 1 [7]. Thinner layers result in smoother surfaces and tighter geometric tolerances at the expense of longer fabrication times; typical layer thicknesses for SLM and EBM are approximately $10 \mu \mathrm{m}$ and $50 \mu \mathrm{m}$, respectively [8], [9].The slicing software then processes each layer to determine the energy source's travel path, spot size, power output, scanning speed, acceptable $\mathrm{O}_{2}$ levels, and in-situ data collection. Files are then transferred to the applicable PBF system to begin fabrication. 


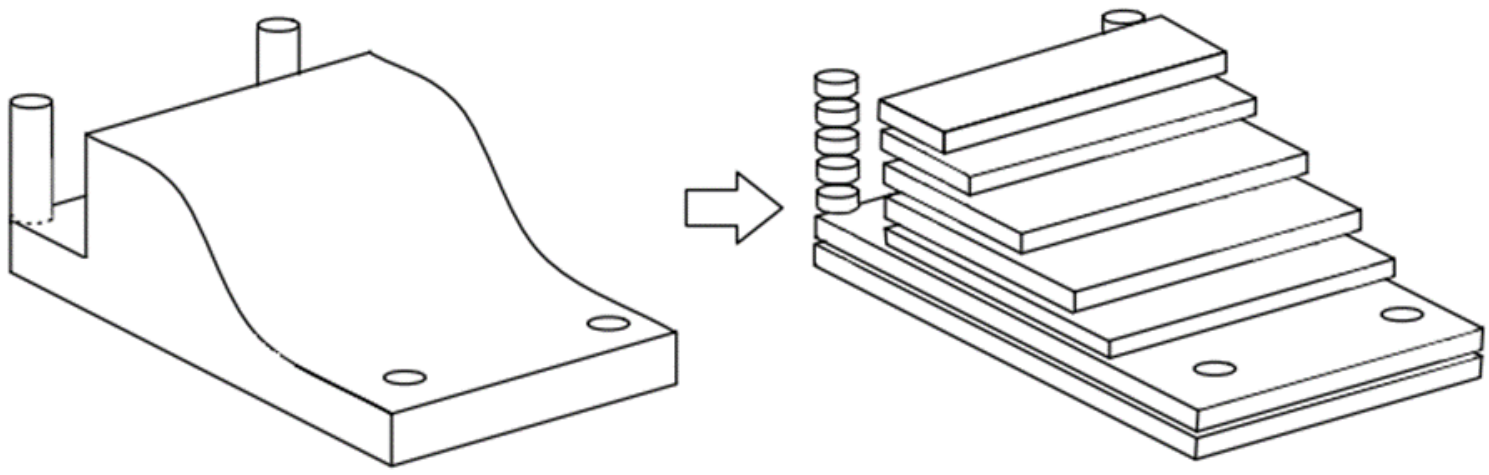

Figure 1: Example component slicing [7].

All PBF systems begin fabrication by controlling the build chamber environment. SLM systems utilize an inert gas such as argon to prevent in-situ oxidation while EBM systems require vacuums to enable the use of an electron beam. One beneficial aspect of the EBM vacuum is the lack of oxygen and other reactive gases that are still present in trace quantities even in inert gas environments. A mechanical rake then distributes a thin layer of pre-alloyed metal powder across a consumable planar metal plate known as a "build plate" or "start plate." Some system manufacturers, such as Arcam, measure and dose a specific amount of powder in front of a rake from a powder hopper located above the system's build chamber; other manufacturers, such as Concept Laser, dose powder by moving a rake across a powder chamber that rises vertically as the component is fabricated as depicted in Figure 2 [10]. If insufficient powder is distributed, the component's outline may not be covered, which may result in skipped layers or misshapen components. Skipped layers that are subsequently covered with powder are problematic due to incomplete interlayer melting, volume reductions when the powder consolidates to a dense layer, and powder swelling in unsupported areas. Improper raking results in many of the same issues in addition to unique difficulties. Powder trapped in the raking mechanism bearings or guides can result in rake "jumping" or "chattering" and leave irregular non-planar powder distributions that are then incorporated in the component. Worn rakes with abraded groove patterns can also distribute powder in a non-planar fashion.

After the first powder layer is distributed, the cross section for the first layer is fused to the build plate by rapidly rastering the energy source and melting powder. The second layer of powder is then distributed on top of the previous layer and the second layer's cross section melts and bonds to the underlying layer; this process is repeated until the fabrication process is complete. Due to the layer by layer nature of material addition, PBF cannot repair worn components except in very limited situations where the used component would be cut and ground down to a planar surface on which to build. 

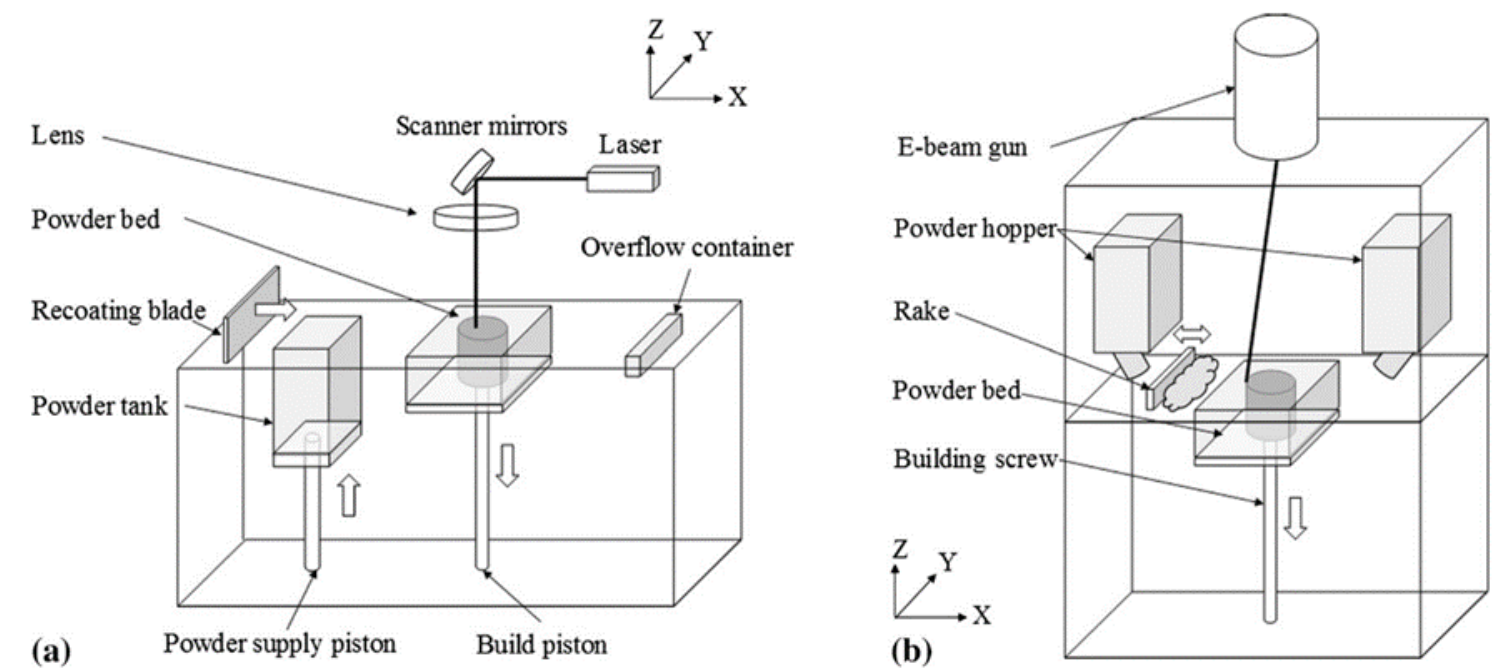

Figure 2: Powder bed fusion system schematics for (a) SLM and (b) EBM [10].

In the case of EBM, it is necessary to wait for the component to cool prior to handling, which can take 580 hours [11] due to holding temperatures in the range of $700^{\circ} \mathrm{C}$ [12]. SLM systems typically operate at or near room temperature and so do not have lengthy cooldown periods. After the component has reached safe handling temperatures, excess powder is removed via brushing, shaking, and vacuuming in the case of SLM and via grit blasting in the case of EBM. EBM processing partially sinters all powder in a build chamber and thus requires kinetic force to dislodge unmelted powder from a component. Components are then cut from the build plate with electrical discharge machining (EDM) or a bandsaw and may be machined to final tolerances for critical surfaces. EBM components typically do not need stress-relieving heat treatments as the elevated temperatures and lower cooling rates relative to SLM effectively provide in-situ stress relief [13]. However, heat treatments to form specific phases may be required, particularly for precipitationstrengthened alloys. SLM components have high as-fabricated internal stresses and stress relief heat treatments are typically required [14].

\subsection{LASER DIRECTED ENERGY DEPOSITION}

Laser directed energy deposition (L-DED) operates by scanning a laser point heat source over a surface, which generates a small pool of molten metal into which feedstock powder is sprayed from a nozzle, as diagrammed in Figure 3 [10]. The sprayed powder that impacts the molten metal is captured, where the powder then heats and melts, adding volume to the pool. As the laser continues traveling, the melt pool cools and solidifies, leaving behind a track of deposited metal, progressively adding mass wherever the nozzle and laser focus. This scanning motion of the deposition head is determined by generating toolpath programing with a CAM software to fill the volume of the desired CAD object file track by track, layer by layer. 


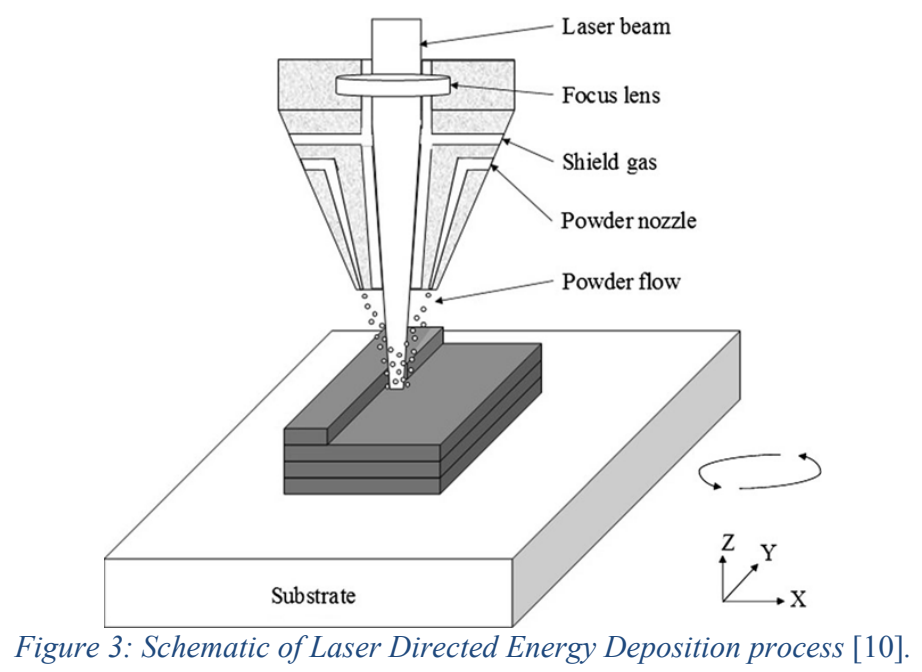

The L-DED process is similar to SLM in many ways as both techniques depend on a scanning laser to locally melt material. Both processes first require a controlled environment to mitigate oxidation of the deposited material. For L-DED, this can either be a hermetically sealed chamber filled with inert gas or, alternatively, an open environment with flowing shield gas, similar to common welding practices. The LDED process is controlled through a number of key parameters such as laser power, laser scan speed, powder flow rate, and the chosen toolpath, which can be either fixed or varied according to control algorithms and in-situ process monitoring. As discussed in the following technical review, these and other parameters strongly influence the performance of the final deposited part.

\subsection{BINDER JET}

Binder jetting is a powder bed-based AM method similar to inkjet technology. It is different from material jetting in that the binder, not the powder, is jetted in a 2D layer and forms the design one layer at a time. The binder jet process consists of printing, curing, de-powdering, post-processing with sintering or back infiltrating, and optionally, further post-processing such as annealing of surface finishing (Figure 4 offers a detailed look at each of these steps).

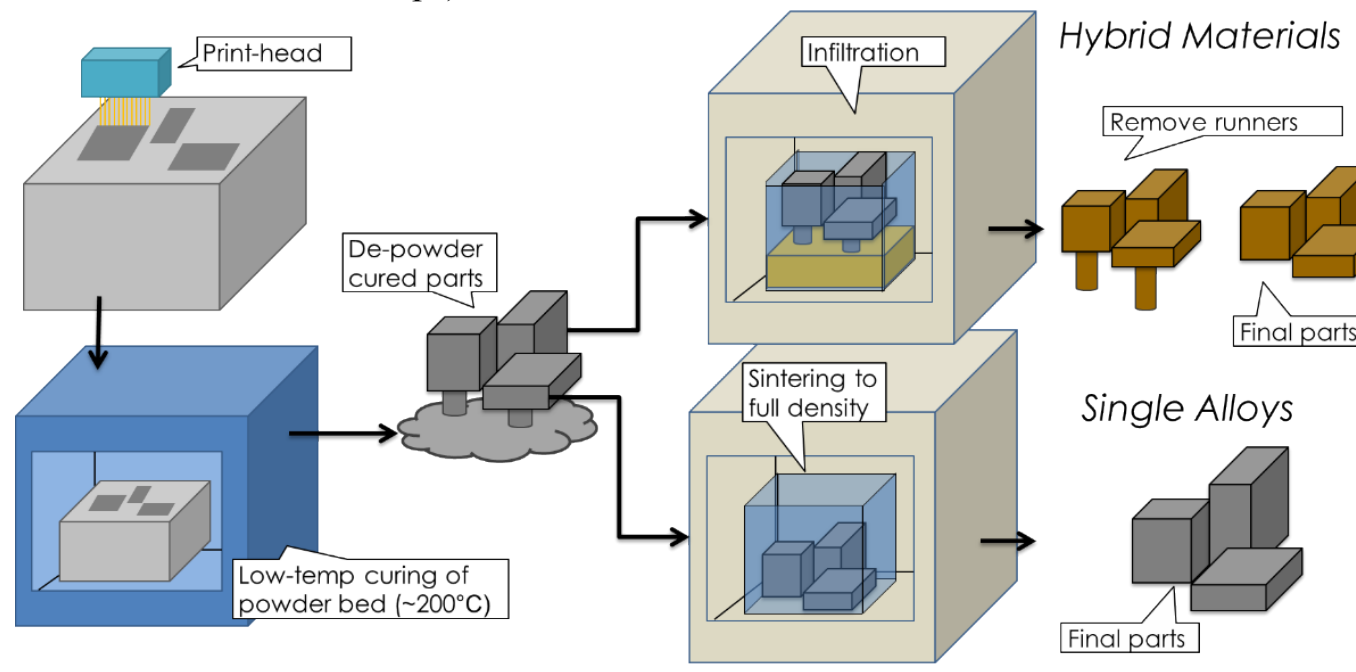

Figure 4: Binder jet process cycle (courtesy of Amy Elliott). 
The first step in binder jet printing is to spread and smooth powder across the build area, which is usually done by a roller. Next, an inkjet-type print-head deposits a binder, which consists of a solution of solvent and polymer, in the current layer of the component specified by the CAD file. Powder is spread and binder deposited repeatedly until the part is complete. The print-head is made up of multiple nozzles and can simultaneously deposit binder across the length of the head, so numerous parts can be printed simultaneously without increasing build time.

When the print is complete, the entire powder bed is moved to a curing oven to remove the solvent and cure the binder. Depending on the machine, the powder bed may be detachable for easy transportation to the curing oven. Otherwise, the powder bed must be carefully extracted from the machine without shifting the print. Curing typically takes 1-8 hours based on the size and geometry of the print and depending on the binder composition. Typical curing temperatures are in the range of $200-400^{\circ} \mathrm{C}$. Next, the cured part must be carefully extracted from the powder bed and de-powdered. At this stage, the component strength is comparable to chalk and so must be handled with care to ensure that it does not break during extraction and de-powdering. Figure 5 shows a successfully extracted part being de-powdered [15].

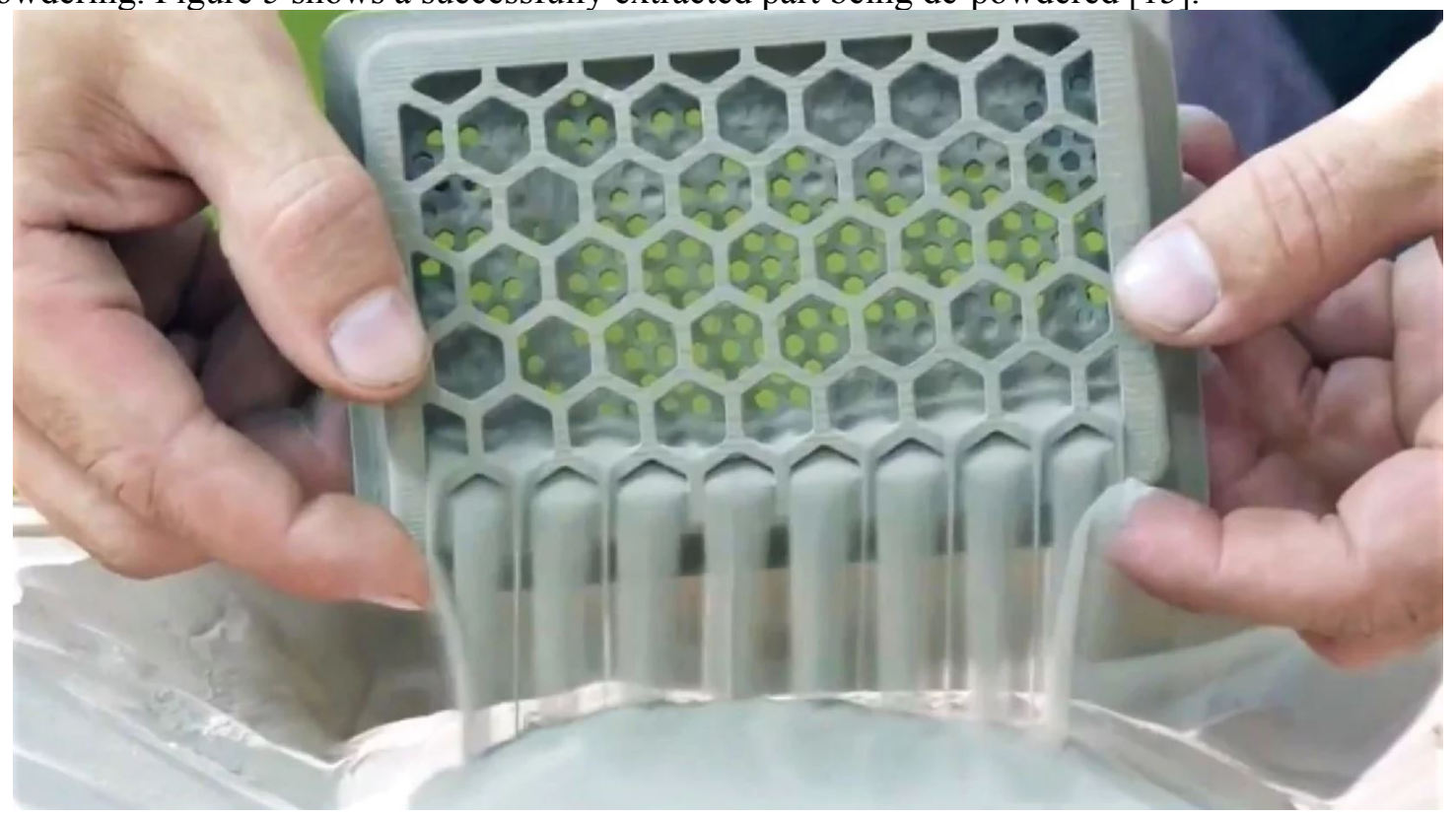

Figure 5: Part being de-powdered [15].

After de-powdering, the part is in a "green" state, which is essentially a fragile bound-powder part with low density (typically $30-50 \%$ dense) that requires further processing to achieve practical mechanical properties [16]. To gain meaningful properties, the green part must be densified by infiltration and/or sintering. Green parts are commonly infiltrated with polymer or melt infiltrated with a metal of lower melting temperature compared to the powder that is printed (such as stainless steel powder infiltration with bronze) to provide mechanical integrity [17]. ORNL has also developed a new approach that exploits chemical vapor infiltration (CVI) to make single constituent or hybrid components. While polymer or liquid infiltration are common practices, there is also a large focus on densifying green powder parts via sintering to form fully dense, single-alloy metal and ceramic parts [18], [19].

Sintering and infiltration are conducted in a furnace. In this final stage, the part is placed in a crucible with infiltration runners or sintering setters. Sintering works by heating the part to a temperature below the melting point of the material but high enough for the material to form necks between particles due to surface tension $\left(>0.8 \mathrm{~T}_{\mathrm{m}}\right)$. Various sintering methods result in more or less densification and shrinkage; therefore, a combination of methods is often used to create the desired outcome. Liquid infiltration operates by capillary forces wicking a secondary molten material into the porous component. Infiltration is advantageous because it results in minimal shrinkage, in any, since densification is achieved with the mass addition the same or a of secondary material instead of densification from shrinkage. However, infiltration 
with secondary materials does result in generally inferior properties relative to a single alloy. At the same time, dissimilar phases bound together often experience different radiation damage effects and resulting stresses that will likely degrade the mechanical integrity of the part. While shrinkage and distortion are drawbacks of sintering, the process does result in a dense single-alloy part. CVI densification route is unique in that it can offer a single constituent material that does not shrink. This is key in allowing the realization of high purity and quality components that conform to the geometrical specifications of the original CAD file.

After the part has been sintered and/or infiltrated, it is considered dense ( $<90 \%$ theoretical density is targeted). Further post-processing is not always necessary but may be done to improve the surface finish, achieve specific phases, or add coatings.

\section{ADDITIVE MANUFACTURING TECHNICAL REVIEW}

\subsection{POWDER EVALUATION}

Feedstock powders must be evaluated and carefully selected based on elemental composition, flowability, internal porosity, particle geometry, size distribution, and surface features to minimize or eliminate several fabrication issues. Many powder manufacturers publish information on the sieve sizes used in production or the mean particle size, however the D10, D50, and D90 (particle size at which $10 \%, 50 \%$, and $90 \%$ of particles are respectively of equal or lesser size) of a particle size distribution should be documented. Two methods of determining powder characteristics are scanning electron microscopy (SEM) and energy dispersive X-ray spectroscopy (EDS) [20]. SEM can be used to image dispersed samples of metal powder, typically against highly contrasting and conductive backgrounds such as carbon, to identify individual particles and the particle size distribution. SEM can simultaneously provide qualitative information on particle shape and presence of satellites. EDS is a well-established method of determining rough elemental composition, and if particles are sufficiently well dispersed when imaging it is possible not only to determine the composition of the overall sample but also individual particles. Analysis of powder characteristics and their measurement have been described elsewhere [21], [22].

\subsubsection{ELEMENTAL COMPOSITION}

Control over the elemental composition of metal AM components is critical to ensuring quality control and predictable properties. As a result, virtually all systems utilize pre-alloyed powders to achieve high elemental control and homogeneity [8]. The elemental composition of fabricated components may deviate from that of the feedstock due to four primary causes: powder cross-contamination, melt pool vaporization, oxidation of feedstock, and oxidation of the melt pool. Melt pool oxidation is minimized by operating in a vacuum for EBM and by utilizing high-purity inert gas environments for SLM and L-DED [23]. Powder cross-contamination is known to be a serious area of concern and can only be solved by either dedicating machines to a single feedstock or meticulously cleaning during powder changeovers. Metal vaporization may be a concern for elements with high vapor pressures [24], but the high travel speed of the melt pool means any location on the build surface is only momentarily molten before solidifying. One study on Ti6Al4V demonstrated the ability to numerically predict the vaporization mass loss for selected elements in an Arcam melt pool and experimentally demonstrated a mean aluminum loss of $0.12 \mathrm{wt} \%$ per melt cycle over five melt cycles [25].

One way to reduce the cost of PBF components is to recycle powder; some systems, such as the Concept Laser X-Line, automatically sieve and store recycled powder in a closed loop inert gas environment whereas other systems expose recycled powder to air during handling and sieving. The latter method may alter the 
chemical composition of powder over multiple reuse cycles via oxidation. In one study, Ti6A14V powder repeatedly recycled and exposed to air in an Arcam electron beam PBF system revealed an oxygen increase from $0.08 \mathrm{wt} \%$ to $0.19 \mathrm{wt} \%$, aluminum decrease from $6.47 \mathrm{wt} \%$ to $6.37 \mathrm{wt} \%$, and vanadium decrease from $4.08 \mathrm{wt} \%$ to $4.03 \mathrm{wt} \%$ over 21 cycles [26]. Another recent study by NIST evaluated a number of powder characteristics for S17-4 PH stainless steel powder reused over 11 cycles and concluded that there was no statistically significant difference in powder microstructure, morphology, size distribution, chemical composition, or mechanical properties of fabricated specimens; powder bed packing density and flowability improved with increasing cycles [27].

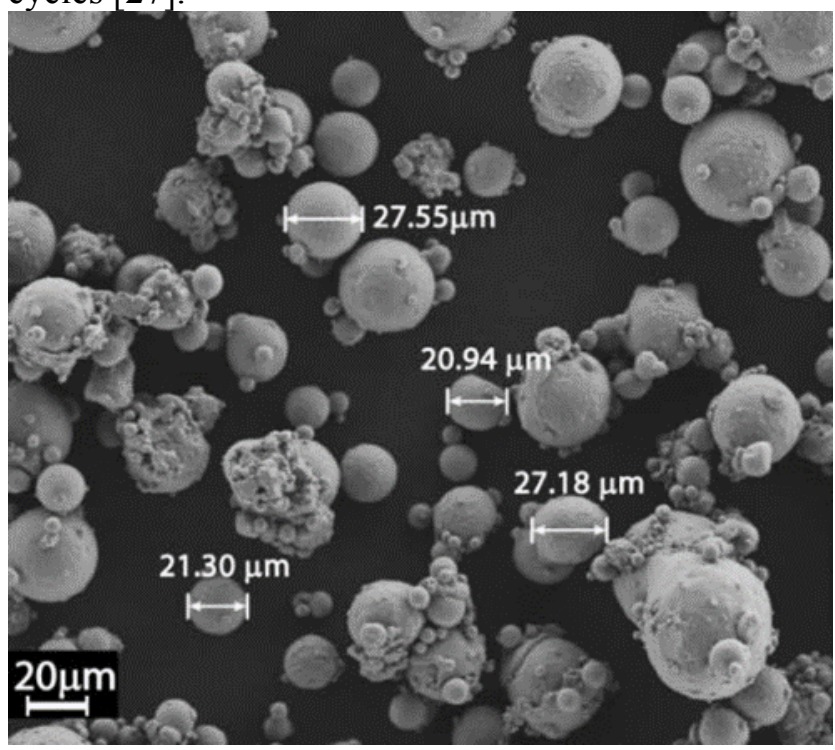

\subsubsection{POWDER POROSITY}

Internal porosity and trapped gas in powders can result in porosity in metal AM fabricated components [35]; therefore, it is desirable to minimize internal porosity in feedstocks. Porosity in components resulting from gas entrapped in powder can be recognized by spherical voids whereas fabrication process induced porosity tends to exhibit irregular and elongated voids as seen in Figure 6 and Figure 7 [8], [36]. Powder porosity is largely dependent on the production technology used. Powders produced via plasma atomization or plasma rotating electrode process (PREP) have been shown to eliminate voids resulting from gas entrapped in powder [35]-[37] whereas gas atomization yields powder with significant quantities of entrapped gas as seen in Figure 8 [36]. Gas atomization and rotary atomization respectively yield powders with satellites and irregular shapes, which adversely affect flowability and powder packing density. Another powder production technique that has been evaluated for PBF applications is hydride-dehydride (HdH) [38]. Bulk metal is converted to a metal-hydride via gas-solid chemical reaction. The resulting phase transformation results in significant $(>15 \mathrm{vol} \%)$ expansion that in turn produces significant stresses, pulverizing the brittle hydride into powder. The hydrogen then subsequently removed by heating the hydride under vacuum, recovering the metal in powder form. HdH powder has been shown to have difficulties with high levels of porosity, but porosity could be reduced by a "double melt" method and hot isostatic pressing (HIP). Analysis of process parameters on powder-induced and process-induced porosity has been reported elsewhere [39]. 


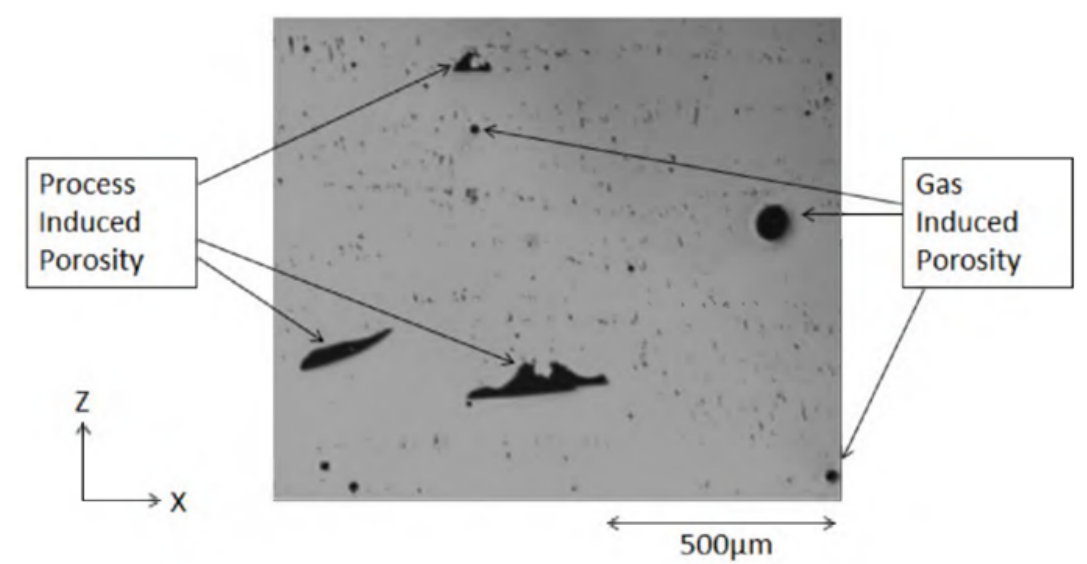

Figure 6: Process induced porosity versus gas induced porosity [8].
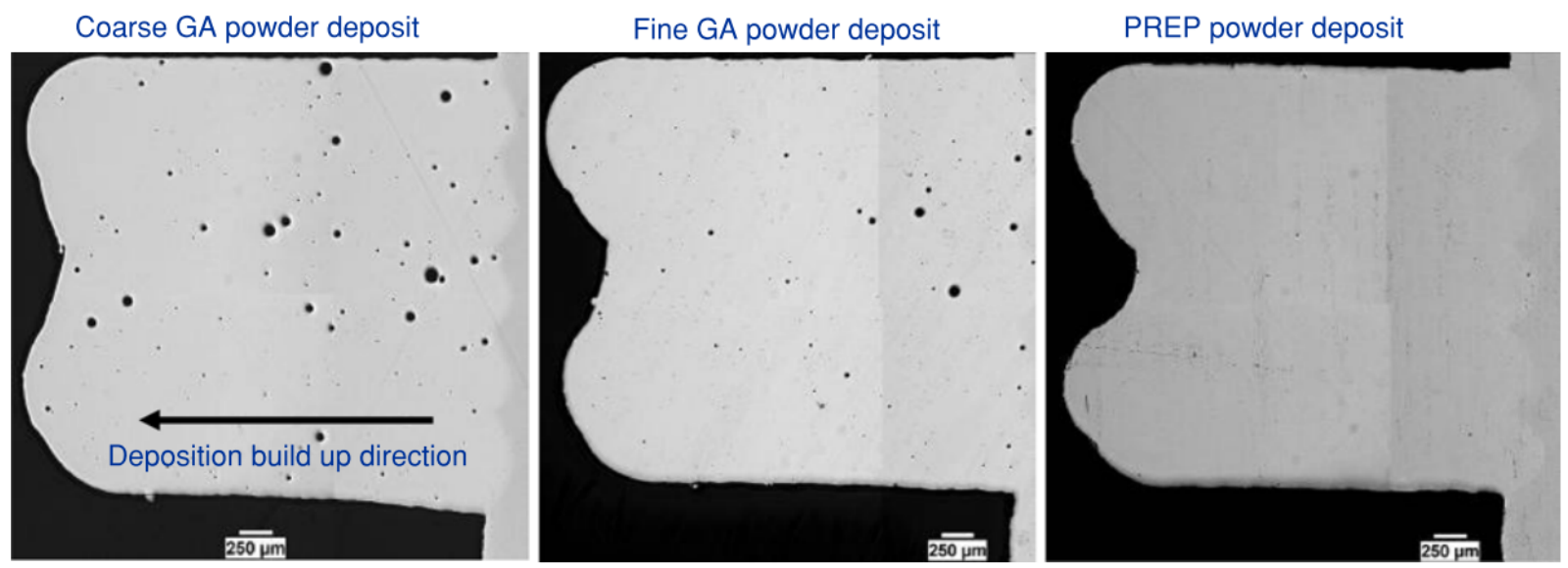

Figure 7: Examples of powder induced porosity [36].

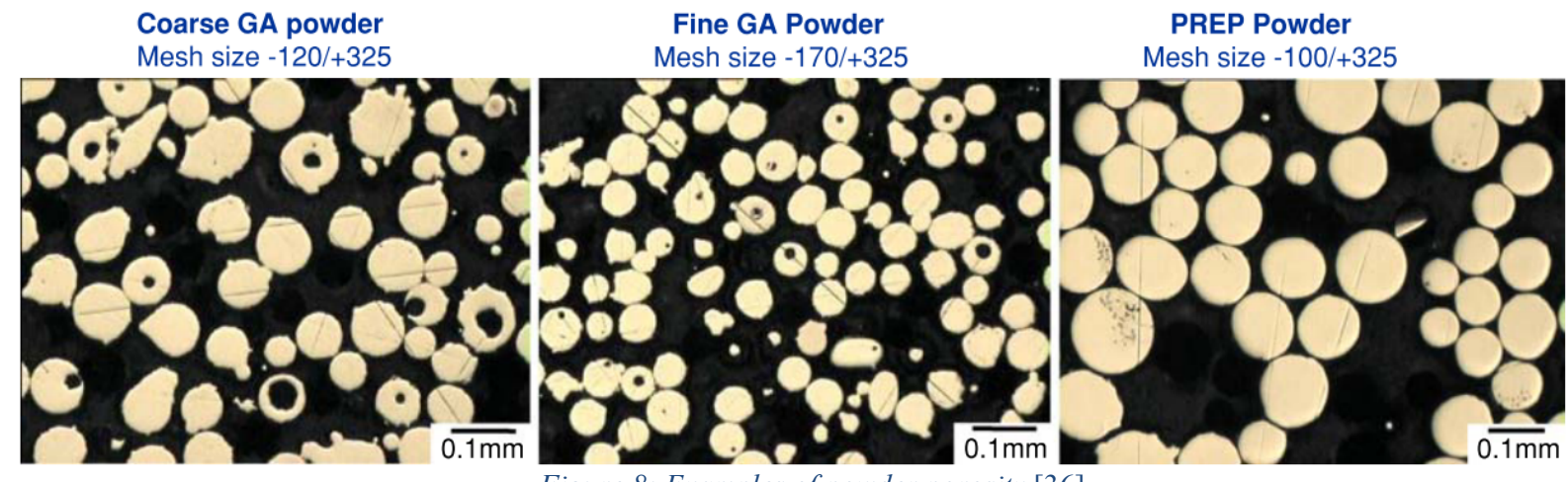

Figure 8: Examples of powder porosity [36].

\subsection{FILE PREPARATION}

File preparation consists of machine instructions on the energy source scan path, timing of turning the energy source on and off, layer thickness, energy source spot size, energy output, environmental parameters, and coater parameters. The machine parameters and scan strategy utilized must ensure complete fusion 
while avoiding issues such as melt pool balling, delamination, porosity, warping, and unacceptable residual stresses.

Scan strategy in the context of PBF refers to the path the energy source travels during the melting process. Multiple scan strategies such as bi-directional rastering, uni-directional travel, and chequerboard/island have been developed as illustrated in Figure 9 [40]. Scan strategy optimization depends on whether the objective is build time minimization, thermal gradient reduction, or surface finish quality as well as the limitations of the PBF system. EBM is capable of near instantaneous movement of the energy source due to electromagnetic field control whereas SLM must physically adjust the mirror position. In PBF terminology, the outside surface of a cross section is the contour and the interior of the cross section is infill. Uni-directional and bi-directional infill scanning have historically been prevalent due to high efficiency and the simplicity of programming; however, these two strategies develop higher thermal gradients and, therefore, internal stresses. Island scanning melts randomized uni-directional or bidirectional patches in a checkerboard pattern as a compromise between the efficiency of bi-directional scanning and the thermal gradient reduction of randomized spot melting and has been shown to reduce residual stress [41]. Spot melting is often utilized to melt the contours of EBM components prior to infill melting whereas SLM typically uses a continuous line melt on contours after infill melting to achieve superior surface finishes [41]. The elevated temperatures of EBM heat partially sinter the entire powder bed; contours melted after the infill tend to develop higher rates of satellite formation and, therefore, coarser finishes [8].

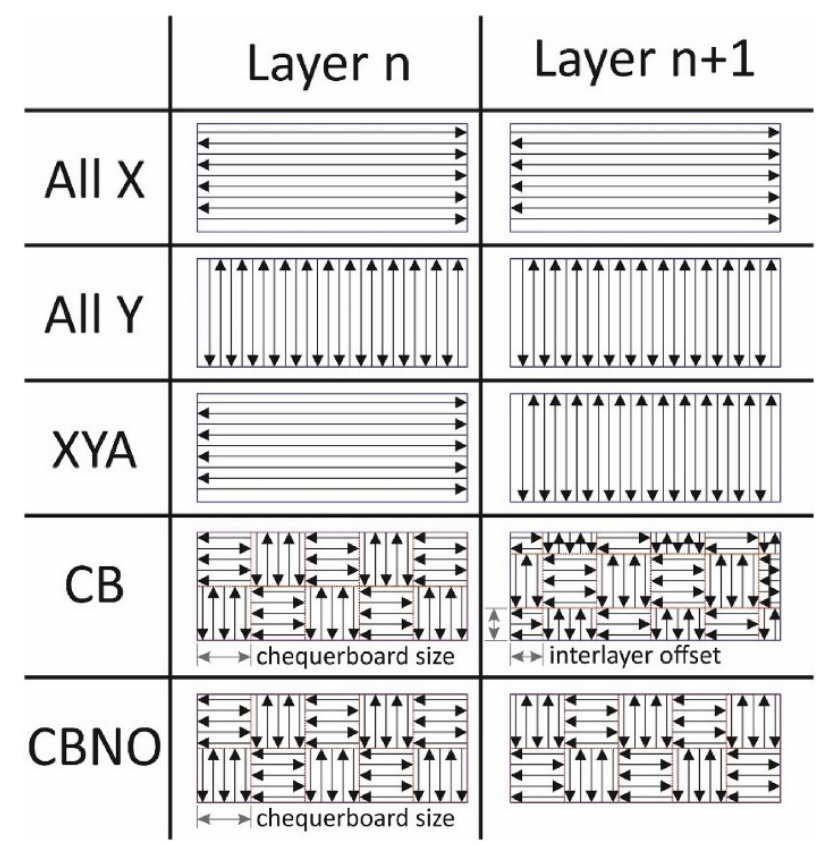

Figure 9: A variety of commercially available scan strategies [40].CB:Chequorboard with interlayer offset. CBNO:Chequorboard with no interlayer offset.

In practice, many PBF systems provide significant flexibility to operators in choosing whether contours will be melted prior to or after infill, scan strategy, inter-layer pattern rotation, line width, melt pool travel speed, and other parameters that directly affect the thermal history of a specific location within a component, porosity, surface quality, yield and tensile strength, and other qualitative and quantitative outcomes. Process parameters must be coordinated to control the critical relationship between thermal energy output and melt pool velocity. At the time of this review, most PBF systems do place restrictions on scan strategies such as uniform layer thickness and uniform spot sizes throughout the fabrication process, constant energy source velocities, and constant delay periods to dissipate thermal energy between layers. Non-constant and non-linear parameters for these currently-restricted parameters along with closed-loop 
control systems are significant technological challenges but offer the possibility of solving additive manufacturing issues such as intra-component yield and tensile strength variation.

Scan strategy for L-DED systems differs from PBF as the motion of the energy source is limited to the relative mechanical speed of the deposition head to the part. This slower speed prevents efficient use of spot melting and island scan strategies, as travel time between areas results in spraying unused powder and higher overall build times. Strategies are frequently chosen to be a contour followed by an internal XYA raster, or multiple contours only for thin wall components. Additional scan strategies are available for 5+ axis deposition.

\subsection{POWDER BED FUSION DESIGN CONSIDERATIONS}

PBF additive manufacturing has revolutionized design in fields where it has been applied, particularly for components redesigned to utilize the advantages of additive manufacturing. PBF does not require straight lines, conventional simple geometries, or direct lines of sight for internal features. Design is, however, limited by four major obstacles. The simplest limitation is the build chamber size of the PBF system. GE's ATLAS machine is capable of fabricating components up to $1.1 \times 1.1 \times 0.3 \mathrm{~m} \mathrm{[42]} \mathrm{and,} \mathrm{to} \mathrm{the} \mathrm{authors'}$ knowledge, is the largest commercially available PBF system. Most manufacturers' systems are considerably smaller with build volumes of $200 \mathrm{~mm}$ cubed to $250 \mathrm{~mm}$ cubed. Components must fit within the build volume of a PBF system during fabrication, which imposes a size limitation.

The second limitation is overhangs and unsupported surfaces. PBF bonds one layer to the previous layer and for an overhang, there is no supporting layer under the melt pool, but rather, loose powder. The lack of substrate supporting the melt pool leads to several issues including swelling, rough bottom surfaces, curling, and inconsistent heat transfer properties within the fabrication process. Swelling occurs when melted material rises above the powder bed plane as shown in Figure 10 [8]. The primary cause of swelling is surface tension of the melt pool, similar to humping in welding, and is directly related to melt pool geometry [35]. Underside surface roughness is impacted by powder particles sintered or partially melted onto the bottom surface of the unsupported melt pool. Curling of unsupported surfaces occurs when new layers on a build solidify and contract upon cooling, warping previously deposited layers. Fabrication of overhangs is possible using support structures of lattices [43] and wafers to provide thermally conductive paths and mechanical anchoring to counter thermally induced stress. Limited unsupported overhangs are possible, though, and the maximum angle depends on the material used.

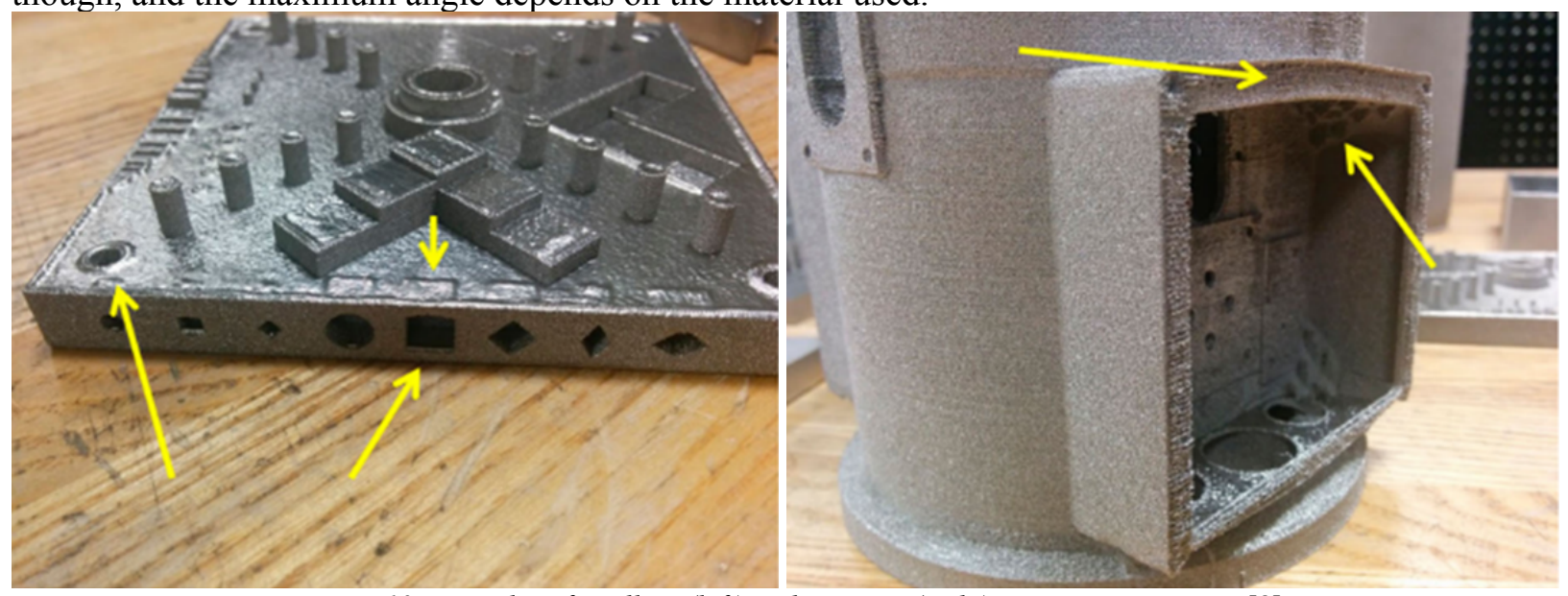

Figure 10:Examples of swelling (left) and warping (right) in EBM components [8].

The third limitation in PBF component design is anisotropic material properties. Columnar grain structure in PBF systems has been well documented [14], [44] and leads to anisotropic or transversely isotropic material behavior with the yield and tensile strengths typically being higher in the build direction (Z-axis) [45]. As a result, the build orientation, load path analysis, and PBF limitations on overhangs must be 
considered simultaneously when designing components. The orientation of the component in the build chamber will determine the isotropic property plane, and limitations on overhang angles preclude certain geometries. Designers can utilize geometries not possible with conventional manufacturing (particularly organic shapes, which can reduce stress concentrations) to redirect load paths in optimal ways. When properly accounted for and incorporated into a design, anisotropic behavior is not problematic as evidenced by the extensive use of fiber reinforced composites with anisotropic properties. Recent work has focused on understanding and controlling the columnar-to-equiaxed grain transition [45]-[47] and describing the transition as a process map [48] in order to selectively form the grain structure of choice.

Surface finish and minimum feature size present the fourth limitation in PBF component design. Surface finish is generally a qualitative aspect of PBF components but may be a major design consideration in the case of internal gas or liquid channels where pressure head losses are relevant. PBF resolutions in the range of 80-250 $\mu \mathrm{m}$ have been reported in literature [49] and are dependent on the energy source spot size and geometric accuracy of the PBF system. It is also important to consider the thermal history of an AM component when designing for critical applications. For example, if ten tensile test specimens are fabricated one-by-one sequentially and removed from the machine when complete, the material properties will be different than had all ten specimens been fabricated simultaneously. In the former case, the component will be built comparatively quickly and so experience a higher mean temperature. In the latter case, the time interval between layers for a given specimen will be greater due to the time spent melting other specimens, and so, more thermal energy will dissipate between layers. Depending on the alloy used and the desired phase or microstructure, this can be used advantageously to control microstructure.

\subsection{L-DED DESIGN CONSIDERATIONS}

The L-DED process shares many of the same design considerations of PBF, but differs in several key ways that alter the approach used in designing processing steps and parameter sets. L-DED does not have a static bed of powder that acts as supporting material. This limits the ability to print undercut features and lattices, which must have a draft angle within the tolerance of the machine design and parameter set. However, the absence of a powder bed also affords several highly attractive design options. Three advantages are discussed: 5+ axis deposition, programmable alloying, and hybrid machining, followed by a discussion of limitations.

The first advantage is that five and six-axis programming permits additive deposition in any direction given appropriate tool clearance, which mitigates draft angle limitations. The maximum dimensions of deposited parts can be substantially larger than those of PBF as the remaining volume does not have to be filled with unused powder, and the deposition head can be traversed through large motions. While many systems use a three-axis gantry, some designs incorporate industrial robotic arms or conveyor belt style single-axis motion for very large and long parts. These more directly incorporate the wealth of available equipment and expertise from subtractive $\mathrm{CNC}$ machine design.

Second, a feature afforded in several commercial L-DED systems is the ability to simultaneously combine powder streams from multiple powder hoppers containing different alloys, which allows customizable alterations to the local deposited alloy composition. Smooth changes in composition between highly disparate materials can be achieved, which is termed a functional graded material (FGM). This permits transitions between non-weldable combinations of materials, or local modulation of properties [50]. This has been applied to create an Invar low CTE mirror backed with SS304L, automobile valves with low elastic mismatches between head and stem, among many others [51].

Finally, an additional significant advantage of L-DED lies in hybridizing AM with traditional CNC subtractive machining. As many L-DED designs already use the same motion systems of traditional CNC, hybrid machines can potentially provide greatly extended machine capabilities at low marginal capital cost. Hybrid machines can switch between printing and machining at any time, facilitating precision-machined 
surfaces on previously impossible to reach places, such as the internals of cooling channels. This capability also enables rapid alloy development through high throughput fabrication [52].

While the L-DED process affords many expanded degrees of freedom, several drawbacks exist. First, commercial CAM options are limited for machine designs that leverage 5+ axis, FGM, or hybrid techniques. Traditional machining toolpath generation does not consider the necessary heat transfer from the laser, through the melt pool, and dissipation in the part. Many of the CAM software solutions being developed for additive manufacturing are three-axis only as it is conceptually simpler and more relevant to PBF. Second, laser scanning is achieved through physical motion of the deposition head relative to the part, which limits achievable scan speeds and accelerations. To compensate for this, melt pool sizes are increased to reduce the number of scans the machine must complete and reduce print time. A larger melt pool also assists L-DED by increasing the fraction of powder that is deposited versus missing the melt pool and scattering into the chamber. However, the larger melt pool size limits the minimum thickness of features that can be printed, which is typically on the order of $500 \mu \mathrm{m}$.

\subsection{BINDER JET DESIGN CONSIDERATIONS}

In general, additive manufacturing provides the freedom to print highly complex parts with fine features, but there are some concerns when making parts layer by layer [53]. Some of these concerns are that the layer by layer deposition creates a "stair-step" effect that compromises the ability to realize very fine features, accuracy, and resolution. Small features and thin walls may not withstand the stresses present during printing or post-processing. Sharp features and high aspect ratios amplify the stresses that occur during printing. Additionally, initially trapped material in the support structure created for overhanging features must have a path for removal [54]. Most of these restrictions apply to binder jetting and there are few instances where these rules can be broken to provide quality parts (e.g., hollow parts can have a designed hole for material removal that is later repaired). The major binder jet design considerations are shown in Figure 11 [55]. 

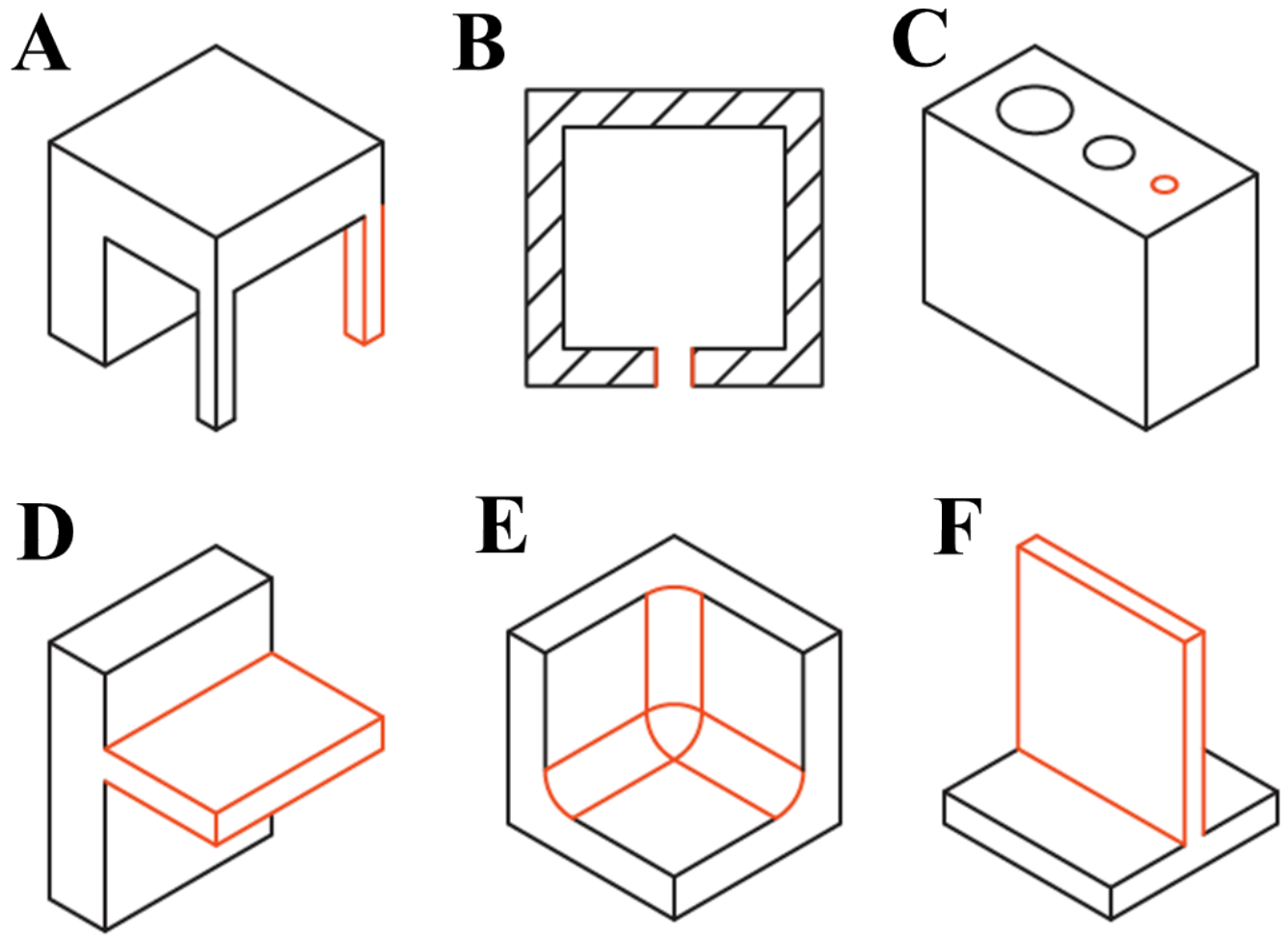

Figure 11: Design considerations when using binder jetting [55].

Freedom in the design of parts made via binder jet technology is a major advantage. Inner channels as in Figure $11 \mathrm{~B}$, fine features as in Figure $11 \mathrm{C}$, and curved surfaces as in Figure $11 \mathrm{E}$ are achievable. This is because the resolution of the printing process is close to $100 \mu \mathrm{m}$, which is among the best of AM techniques [54]. Some guidelines to follow on design considerations for binder jet include avoiding designs where thin features support large masses as in Figure 11 A, unsupported thin walls as in Figure $11 \mathrm{D}$, any feature that would be difficult to de-powder such as large cavities or holes as in Figure $11 \mathrm{~B}$ and $\mathrm{C}$, and allowing direct paths for build material to exit from holes and cavities [55].

In binder jetting, if there are thin features supporting large masses, the green part could be compromised because of low strength and would most likely crack in the thin section when de-powdering. Unsupported thin walls will experience the same problems when de-powdering, but depending on their orientation, they could survive sintering (e.g., small antenna protruding from the top of a larger part). Large masses or areas could adversely affect geometric tolerance when sintering due to shrinkage. Additionally, large cavities are difficult to de-powder. Enclosing hollow volumes is virtually impossible in binder jet unless a designed hole is subsequently plugged.

The limitations of binder jetting include green part strength, green density, compatibility with binder, furnace size, and post-processing to fully densify parts [54]. The green density and strength are typically low, so the green parts do not always survive de-powdering and transferring to a sintering or infiltrating furnace. Large binder jet components face the additional requirement of sufficiently large furnaces for sintering or infiltration. Further, the shrinkage and warping of large, complex parts with sintering and infiltration is another issue to consider when designing binder jet parts. 


\subsection{CRACKING AND DELAMINATION}

Two types of cracking have been observed in AM components [56] in addition to inter-layer delamination. Solidification cracking occurs when the tensile stress in the solidified regions of the melt pool exceeds the material's yield strength and is also observed in welding [41]. Solidification as well as thermally induced contraction in the solid-state result in local tensile stress, but displacement is inhibited by bonding with substrate layers. The second type of cracking is known as liquation cracking or grain boundary cracking and is observed at grain boundaries in partially solidified regions of the melt pool. Upon solidification, some phases nucleate first and begin contracting before the remaining material has solidified, and the liquid inter-grain region can act as a crack nucleation site. Several material characteristics have been related to liquation cracking and include large differences between the solidus and liquidus temperatures (as with $\mathrm{Ni}$ superalloys [41]), large melt pools due to low thermal conductivity (as in with Ti6A14V), and large coefficients of thermal expansion (as in with aluminum alloys) [57]. Literature on the causes and mitigation of cracking in Ni superalloys has been published [41]. Finally, delamination occurs due to residual tensile stresses in the solidified region exceeding the layer interface yield strength [58]. Delamination can be caused by either incomplete melting of powder feedstock or insufficient remelting of underlying layers to achieve high inter-layer strength. Incomplete melting of feedstock and the resulting internal porosity may be largely remediated by hot isostatic pressure post-processing, but cracking and delamination cannot be remedied by post-processing. If porosity is sufficiently high, macroscopic cracking can occur due to stress concentrations, thereby causing the residual stress to exceed the strength of the material. It has been demonstrated that macroscopic cracking in SLM can be reduced via substrate heating [56].

\subsection{RESIDUAL STRESSES AND SUBSTRATE WARPING}

Build plates are used in PBF and L-DED systems to provide adherence for the first layers of a component [35] and provide a planar starting surface. Substrates may be unheated, heated via internal heaters, or heated via electron beam in the case of EBM. There are many reasons for substrate heating, including in-situ stress relief, decreasing thermal gradients between the melt pool and previously deposited layers, or forming phases or microstructures that require specific thermal conditions [59]. Substrates may be composed of the same material as the component to minimize differences in coefficients of thermal expansion, cost-effective materials, or alloys that form brittle interfaces with deposited materials for easy removal (e.g., Ti6Al4V deposited on SS304). However, substrate warping may occur [60] if the thermally induced residual stresses exceed the yield strength of the substrate, thereby causing plastic deformation.

Thermally-induced strains and residual stresses are an inherent aspect of PBF and L-DED as liquid metal is deposited on a comparatively cooler underlying material [59], [61]. Residual stresses can cause delamination, cracking, and warping, all of which will result in failed fabrication. Accurate understanding and modeling of thermal stresses and in-situ heat transfer can facilitate optimal processing parameters and placement of sacrificial heat dissipation supports attached to a component. Residual stresses in PBF components tend to be concentrated near the substrate interface, tensile near edges, and compressive in the interior [13], [62]-[64]. Mechanical support structures may be used to lift the component off the build plate and slightly reduce residual stresses due to the supports having higher initial temperatures than the build plate [59]. Residual stress may be relieved when a component is removed from the build plate via deformation [62].

Residual stress in PBF is affected by scanning strategy, and the effect of island scanning on residual stress has been reported [60], [65]. Direct comparison of the effect of scan strategies is difficult due to incomplete fabrication parameter reporting in literature. SLM typically produces higher residual stress than EBM due to the larger temperature difference between the melt pool and substrate as well as in-situ stress relief in EBM. Residual stress in as-fabricated EBM components has been reported at 5-10\% of the ultimate tensile 
strength (UTS) [13], and residual stress in SLM pure iron has been reported at $60-80 \%$ of the yield strength [14].

Characterization of residual stress may be achieved by several methods including neutron diffraction [66], [67], X-ray diffraction [59], [68], the contour method [67], [69], microhardness [70], and hole drilling [71]. Microhardness may be used for single phase alloys but only provides information about residual stress at the surface. The contour method utilizes deformation measurement after cutting a sample (i.e., EDM), which provides comparable data to neutron diffraction [72] with less influence from elemental composition but is a destructive measurement method. X-ray diffraction and neutron diffraction can both measure residual stress but require expensive specialized equipment. Finite element analysis modeling has been used to predict residual stresses in SLM [73], and simplified thermal cycle modeling has been reported to qualitatively correlate with experimental substrate warping [74]. A thorough review of AM residual stress origins, modeling, and remediation has been published [75].

\subsection{POWER DENSITY}

Three variables are most commonly cited as the determining factors in thermal energy transfer to the melt pool: power, spot size, and scan speed. Power output and scan speed are linked by the need to control the melt pool geometry and form fully dense components. Process mapping has emerged as a method of describing the power-speed relationship useful to PBF and other metal AM methods and is similar to welding process mapping [76]. One representative EBM process map for SS316L is shown in Figure 12 for reference [77]. Two serious issues with non-viable combinations of speed and power are melt ball formation and delamination as shown in Figure 13 [77]. Melt ball formation occurs due to melt pool instabilities when the surface tension of the melt pool exceeds the wetting ability of the previous layer [78]; melt balls result in fabrication failure due to interference with the rake and non-uniform layer formation. All PBF systems operate by repeated melting of sequentially added layers; delamination will occur when the interlayer bonding strength is exceeded by thermally induced residual stresses due to high thermal gradients, incomplete melting, grain boundary precipitate formation, or other mechanisms. Studies have particularly identified the importance of scan strategy [79] and applied energy input [80] in delamination occurrence; melt balls result in fabrication failure due to interference with the rake and non-uniform layer formation. In L-DED, the scan speed also has the effect of altering the total amount of mass added to the melt pool per

unit length, as the powder feed rate $(\mathrm{g} / \mathrm{s})$ is held constant. This introduces a fourth important control variable which must also be mapped. 


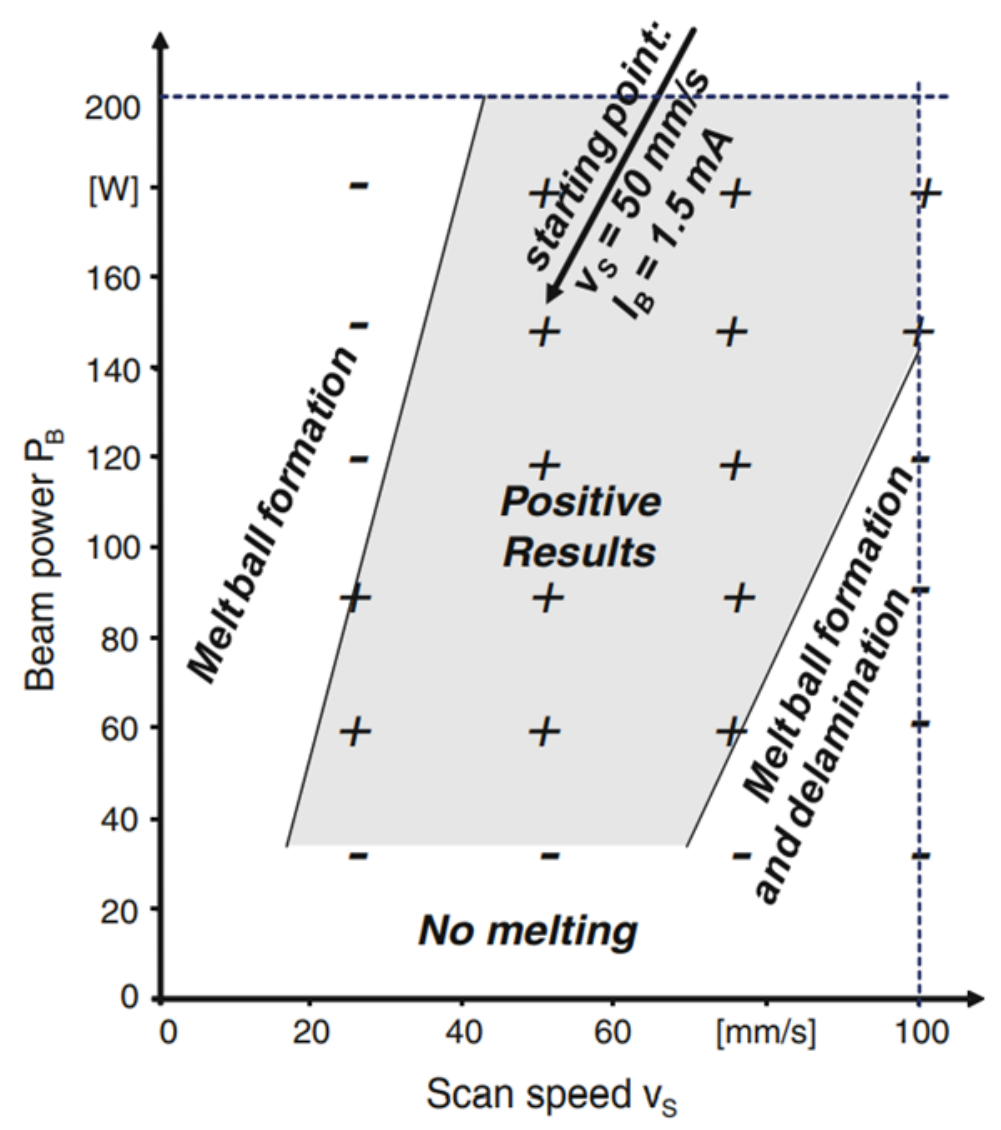

Figure 12: EBM process parameter window for SS316L [77].

A recent study analyzed the effect of spot size by varying the focus plane in SLM. It was demonstrated that, for a constant wattage, out of focus beams resulted in larger spot sizes, lower power densities, and coarser columnar grains [81]. For EBM, larger defocused spot sizes $(500 \mu \mathrm{m}$ versus $400 \mu \mathrm{m})$ resulted in more forgiving process windows with more combinations of speed and power forming dense layers; wider defocused beams were also observed to form more uniform columnar grain structures [82]. In L-DED, larger spot sizes and melt pool sizes have an additional effect - they increase the available surface to capture sprayed powder particles, which increases the fraction of captured particles. This alters the height of the deposited layer as well as the temperature, as the extra introduced particles absorb energy [83]. Larger spot sizes result in less severe thermal gradients, which in turn can reduce internal stresses produced upon solidification. 


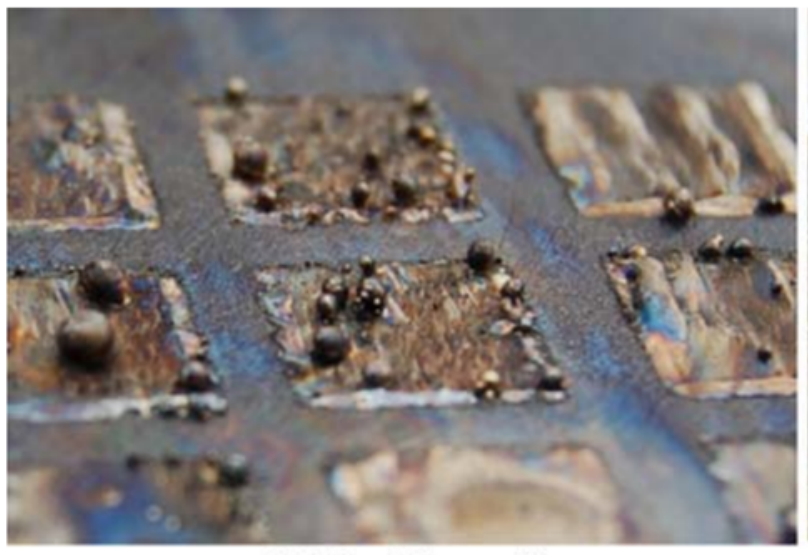

Melt ball formation

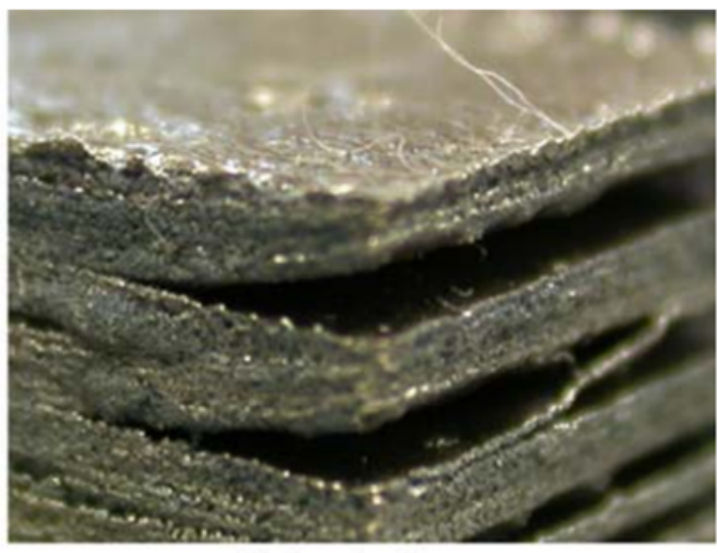

Delamination

Figure 13: Fabrication failure examples due to power-speed relationships [77].

\subsection{THERMAL HISTORY}

One active area of research and process improvement is understanding, modeling, and preparing scan strategies for local thermal histories. PBF melts and rapidly solidifies both the top layer and several underlying layers; layers immediately under the melt pool will experience multiple rapid heating and cooling cycles, which can affect grain size, phase formation, and precipitate formation depending on the ambient temperature of the build chamber, melt pool temperature, material thermal conductivity, time between passes, and component geometry. An example thermal history profile is shown in Figure 14 [84]. In SLM, the build chamber is near room temperature unless substrate heaters are deliberately added. EBM build chambers typically have an ambient temperature of several hundred degrees Celsius and cooling to below $100^{\circ} \mathrm{C}$ can take $5-80$ hours after melting is complete [11]. In L-DED repeated laser passes partially melt and reheat previous layers, similarly producing a 'sawtooth' thermal history profile.

Time temperature transformations and recrystallization are two of the major concerns with accurately modeling and measuring the local thermal history of a component due to the possible loss of strengthening mechanisms. One limitation of current scan strategies in preparing files is that the local temperature and thermal dissipation is not considered. For example, a pyramidal component will have longer time intervals between layers at the bottom than at the top due to the change in cross sectional area. For low layer times this can produce a buildup of heat in the part which modifies the build characteristic and acceptable process parameter window over time [83], [85]. Software packages that accurately model and account for the local temperature might have dwell times between layers at the top of the pyramid in this example.

PBF components are fabricated by spreading a thin layer of metal powder over a planar build plate and then melting the outline of the component with the system's energy source. The second and all subsequent layers consist of metal powder raked across and melted to the previous layer with the melted outline dependent on the component cross section at a given height. Several factors affect performance measures such as interlayer bonding, tensile strength, porosity, and surface finish; these factors include environmental control, powder raking, power density, and control over the thermal history of a component. In-situ data collection is also an important aspect of the fabrication process due to the possibility of correlating observational information with performance characteristics and non-destructively predicting whether a component will fail, where the failure will occur, and the mode of failure. 


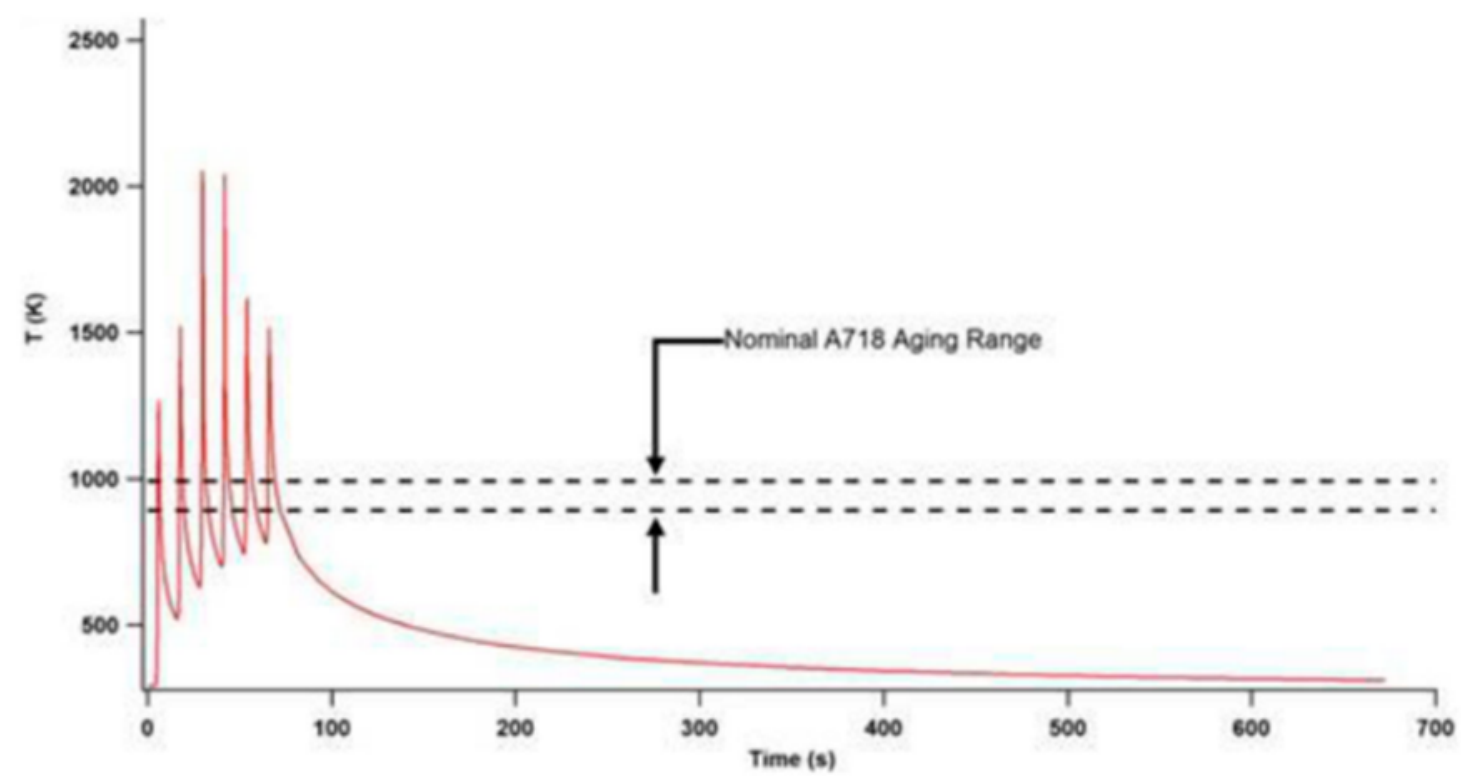

Figure 14: Example thermal cycling simulation [86].

\subsection{ENVIRONMENTAL CONTROL}

Strict environmental control of the build chamber is necessary to achieve desirable and repeatable microstructures and performance characteristics. Many metals tend to slowly oxidize and the large surface area of powders result in accelerated oxidation on a weight basis. Powders exposed to air also tend to attract moisture, which can degrade fabricated component properties if not removed via pre-fabrication heating or desiccation. Molten metal will rapidly oxidize if exposed to air, and for this reason, welding systems have long utilized inert gases as a shielding mechanism. SLM and L-DED systems typically utilize inert gas environments of argon or nitrogen to minimize these deleterious mechanisms; the entire build chamber is flooded with inert gas and oxygen scrubbers may or may not be used to assist in removing residual oxygen. L-DED systems have the additional option of not purging the entire environment of oxygen, but instead locally flowing an inert gas over the melt pool in tandem with the blown powder, similar to gas shielded welding. This does not achieve as low an oxygen level, but it is sufficient to produce fully dense components. EBM processes instead operate in vacuum conditions of $<5 \mathrm{E}-2 \mathrm{~Pa}$ in the build chamber due to the requirements of the electron beam column [8].

\subsection{IN-SITU MONITORING AND CONTROL}

One active area of research for additive manufacturing quality control is in-situ process monitoring and closed loop feedback systems. In-situ process monitoring has been identified as a critical obstacle to robust additive systems [87], [88] due to the high number of process parameters. One study identified over 50 distinct process parameters for SLM [89], and melt pool velocity, power density, and thermal energy dissipation are well-known to affect material properties and successful fabrication completion. In-situ monitoring has previously been reviewed [90], [91] and can be compared in many ways to the process 
monitoring in modern machining systems. As monitoring collects data, it can then be input to a control algorithm that modifies key parameters to maintain desirable processing conditions.

Temperature and geometric positioning are the two most commonly measured in-situ variables; common monitoring methods are cameras operating in the visual, near-visual, or infrared wavelengths and pyrometers. Non-contact methods are preferred to minimize fabrication downtime in addition to the difficulties of utilizing contact measurement methods. In-line cameras have been utilized to observe melt pool electromagnetic radiation and calculate the temperature and dimensions of the melt pool [92]. This method is patented by Concept Laser [93] and implemented in a closed loop to stabilize and control the melt pool. One acute difficulty of camera control of melt pools is the significant data accumulation due to high resolutions. Data must be collected, processed, and commands returned in real time to be of value. Further compounding the difficulty is the need to incorporate macro thermal data of the entire powder bed environment with local melt pool information.

Pyrometers are frequently used for in-situ temperature measurement [91], [94]-[101] as the device allows for in-situ data collection with no adverse effects on the fabrication process. However, pyrometers and cameras are limited to measurement of the powder bed surface, and accurate absolute measurements depend on accurate emissivity values for a given alloy at a given temperature. Cameras have also been utilized for defect detection such as porosity, cracks, and incomplete powder raking [102]. Laser displacement sensors are less commonly used for process monitoring, but have measured in-situ distortion [103] and layer height [104]-[106]. The only commonly used contact measurement device are thermocouples [103], [107]-[109]. Thermocouples are inexpensive compared to pyrometers, high speed cameras, and infrared cameras; however, they are limited to substrate measurement due to the nature of AM.

\subsection{POST-PROCESS NON-DESTRUCTIVE TESTING}

Non-destructive post-process testing of PBF and L-DED components is currently a critical aspect of certification for NPP applications. In-situ monitoring of AM fabrication can exploit the unique layer-wise nature of AM to create a 3D map of a component given a series of 2D data sets for each layer using the methods discussed in Section Error! Reference source not found.. Residual stress measurement methods have been discussed in Section Error! Reference source not found.. While in-situ techniques can inform control algorithms and capture unique information, for qualification, final testing should occur after all post-processing treatments such as HIP, heat treatments, and precision machining. However, the geometric complexity of AM components and frequent mixture of fine details with bulk structures add significant challenges to accurate measurement. Work on non-destructive testing of metal AM components has been published [110] and is an active area of research given commercial interest in fabricating critical components that require inspection and certification.

Porosity in a final component must be characterized with techniques that are sensitive to the size range and type that will impact mechanical properties, particularly fatigue strength. Existing standards for porosity such as ASTM E186 - 15 for cast steel walls may provide useful reference upon which to develop. Porosity can be characterized by material density, number of pores, pore location, pore size distribution, and pore morphology. Comparing a component's actual density against theoretical density is the simplest characterization and can be achieved by the Archimedes principle [111]. Measurement of other aspects of porosity depend upon the resolution desired, material properties (such as X-ray absorbance), and geometric considerations. X-ray-based computed tomographic (CT) is capable of pore measurement to $10 \mu \mathrm{m}$ [112] and work has been published on CT pore measurement in laser welds [113], [114]. Synchrotron radiation micro-tomography $(\mathrm{SR} \mu \mathrm{T})[115]$ has been used to detect pores with a resolution of $1.3 \mu \mathrm{m} \times 1.3 \mu \mathrm{m} \times 1.3$ $\mu \mathrm{m}$, but the measurement area was small at $1.3 \mathrm{~mm} \times 1.3 \mathrm{~mm} \times 10 \mathrm{~mm}$. Although CT and $\mathrm{SR} \mu \mathrm{T}$ are highly accurate, both methods are capital-intensive and may be unnecessary if a HIP post-process treatment is 
standard for a component. In such a case, using the Archimedes principle to determine overall porosity and another method to detect large $\left(>1 \mathrm{~mm}^{3}\right)$ pores may be faster and more cost-effective.

Grain size and orientation can be characterized on the component surface via a range of microscopy based techniques including electron backscatter diffraction and SEM [116]. Data on the internal microstructure is only possible at high resolution with destructive methods. However, sacrificial inspection specimens could be fabricated at the same time as a component under the same processing conditions and thereby offer a measure of assurance.

\subsection{ENERGY SOURCE- POWDER INTERACTIONS}

The energy source utilized in PBF and L-DED interacts with the powder bed and melt pool in a variety of ways depending on the total power applied, the power distribution, and processing environment. Localized boiling of the melt pool is common to both SLM and EBM and results in convective transport liquid or vapor known as "spatter" when the droplet overcomes surface tension [117]. Spatter is observed in PBF and welding as white "fireworks" and is caused by excessively high temperatures in the melt pool. Ejected material is not a concern unless large or frequent enough to interfere with the wiper blade depositing a uniform powder layer. However, boiling the melt pool can result in "keyhole" voids if the energy source moves and the melt pool solidifies prior to the void being filled.

SLM transfers energy to the powder bed or melt pool via photons. Energy transfer is affected by the reflectivity of powders and melt pool [118], and some highly reflective powders cannot be processed with SLM as a result of reflected energy destroying optics and sensors. SLM laser beams are typically distributed in a Gaussian profile; however, research in ring beam shaping has shown the potential for finer microstructures due to more even power distribution [23]. Pulse shaping of Gaussian laser beams (the control of output power over time) has also shown the ability to reduce spatter ejection, improve surface roughness, and decrease melt pool width [119]. Pulse shaping can also be used to effectively preheat powder, thereby decreasing reflectivity and potentially allowing for SLM fabrication of highly reflective powders. Pulse shaping and non-Gaussian beam profiles do significantly increase computational requirements, however, and would be additional variables to control for certification.

In EBM, power is transmitted via electrons, which also result in an electrical charge transfer. Electrical charge buildup can occur and if repulsive electrostatic forces are sufficiently large, physical displacement of powder can transpire in an effect known as "smoking" [120], [121] as shown in Figure 15 [80]. Smoking can be reduced by rapidly scanning a defocused electron beam across the powder bed to partially sinter material before melting and by injecting a small quantity of helium into the build chamber to reduce charging. An important parameter in reducing smoking is the electrical resistivity to bulk density ratio of the powder [120].
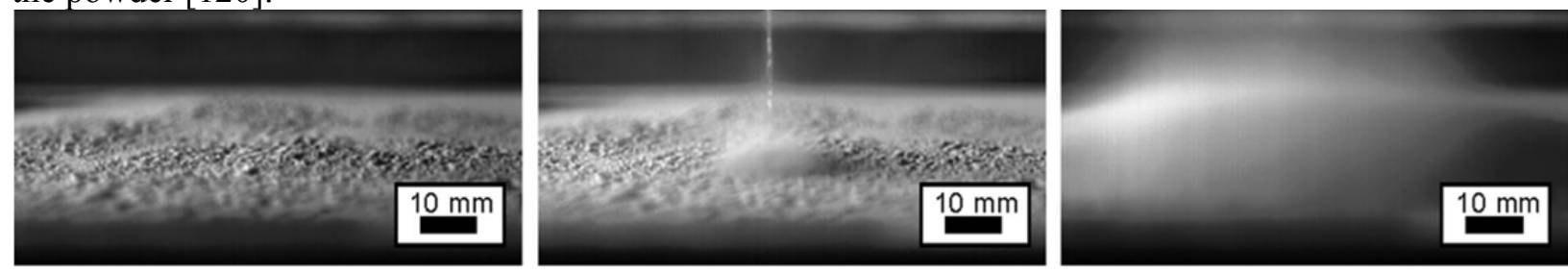

Figure 15: Example of EBM smoking (left to right: $0.000 \mathrm{~s}, 0.005 \mathrm{~s}, 0.010 \mathrm{~s}$ ) [80].

In L-DED, laser powder interactions are significantly different as a) the powder is sprayed and in motion and b) sizes of the melt pool and powder are frequently larger $(0.5-2 \mathrm{~mm}, 50-150 \mu \mathrm{m})$ and melt pool speeds are slower $(10-30 \mathrm{~mm} / \mathrm{s})$. This produces two effects: first, powder in flight will absorb and reflect energy from the laser, which heats and sometimes melts the powder in flight. Much of this energy is carried away from the melt pool, thereby changing the melt pool's energy balance, size, and temperature distribution 
[122]. Additionally, particles that melt in flight will cold weld to surfaces that they impact, introducing additional surface roughness. Second, instead of the laser traversing over a nominally static powder bed, powder will impact the top surface of the melt pool [123]. The particle can either penetrate through the surface, be retained by surface tension and float, or rebound back off of the melt. The specifics of this interaction strongly depend on the material and solid-liquid wettability of the particle to the melt pool.

\subsection{SUBSTRATE AND POWDER REMOVAL}

After fabrication, components must have excess powder removed and be cut off of build plates. SLM, LDED, and binder jet components can be cleaned by brushing and vacuuming whereas EBM components must be cleaned via grit blasting to remove partially sintered powder. Components are typically removed from build plates with EDM or bandsaws. Removing entrapped powder from channels and internal cavities can be challenging and cutting components off of build plates presents handling difficulties for EDM and bandsaws designed for tubular and beam stock. While not technologically challenging, there is an industry need for specialized support equipment.

\subsection{HOT ISOSTATIC PRESSING AND HEAT TREATMENTS}

Hot isostatic pressing is a method in which components are heated in the presence of a high-pressure inert gas environment to close internal pores [124]. Internal cracks may also be remediated by HIP as demonstrated in SLM fabricated Ni superalloy components [41] but surface-connected cracks remained after HIP. The high temperatures of HIP also facilitate grain growth in some situations. Inconel 718 deposited on an Inconel 718 substrate via LENS and subsequently post-processed with HIP was observed to result in grain growth in the substrate but not the deposited material [125]; differences in phases or grain boundary precipitates may have caused the variation in response to HIP. If so, appropriate characterization or homogenization of deposited material prior to HIP is necessary to achieve consistent responses.

The effects of HIP and heat treatment combinations on Ni superalloys [126], [127], [136], [128]-[135], Ti alloys [137]-[139], Al alloys [140], and steels [141], [142] have been reported in literature, and data on the effect of HIP on porosity and elongation at failure is shown in Table 1. The difference in yield strength and UTS between as-fabricated and HIP treated samples cannot be directly correlated due to the oftensignificant effects of phase transformations and precipitation; however, Young's modulus is usually negligibly affected by HIP. Porosity, lack of fusion, internal cracks, and similar defects are reduced by an order of magnitude and treatment times as short as 4 minutes have been shown to reduce porosity as significantly as 3-4 hour treatments [134]. Studies that heat-treated after HIP reported negligible variation in porosity between post-HIP samples and post-HIP heat-treated samples, indicating that porosity reduction is permanent. Elongation at failure was reported to improve by $30-200 \%$ with HIP, however ductility may not improve in cases where highly brittle phases are formed as a result of the HIP temperature profile. Fatigue resistance increases with HIP due to the reduction in internal crack nucleation sites but is similarly difficult to compare because of thermal effects on grain size and phase formation for each alloy system.

Table 1: Effect of HIP on porosity and elongation at failure for PBF components.

\begin{tabular}{|c|c|c|c|c|c|c|c|c|}
\hline Material & $\begin{array}{c}\text { HIP } \\
\text { Pressure }\end{array}$ & $\begin{array}{c}\text { HIP } \\
\text { Temperature }\end{array}$ & $\begin{array}{c}\text { HIP } \\
\text { Time }\end{array}$ & $\begin{array}{c}\text { Pre-HIP } \\
\text { Porosity } \\
(\%)\end{array}$ & $\begin{array}{c}\text { Post-HIP } \\
\text { Porosity } \\
(\%)\end{array}$ & $\begin{array}{c}\text { Pre-HIP } \\
\text { Elongation } \\
(\%)\end{array}$ & $\begin{array}{c}\text { Post-HIP } \\
\text { Elongation } \\
(\%)\end{array}$ & Ref. \\
\hline $\begin{array}{c}\text { H13 Tool } \\
\text { Steel }\end{array}$ & $100 \mathrm{MPa}$ & $1130^{\circ} \mathrm{C}$ & $6 \mathrm{hr}$ & 0.11 & 0.005 & $3.3 \pm 1.6$ & $6.6 \pm 0.6$ & {$[142]$} \\
\hline
\end{tabular}




\begin{tabular}{|c|c|c|c|c|c|c|c|c|}
\hline $\begin{array}{c}\text { Hastelloy } \\
\mathrm{X}\end{array}$ & $103 \mathrm{MPa}$ & $1160^{\circ} \mathrm{C}$ & $4 \mathrm{hr}$ & $0.29-0.34$ & $<0.1$ & - & - & {$[129]$} \\
\hline $\begin{array}{c}\text { Inconel } \\
718\end{array}$ & $120 \mathrm{MPa}$ & $1200^{\circ} \mathrm{C}$ & $4 \mathrm{hr}$ & - & - & $6 \pm 1$ & $14 \pm 1$ & {$[128]$} \\
\hline $\begin{array}{c}\text { Inconel } \\
718\end{array}$ & $102 \mathrm{MPa}$ & $1160^{\circ} \mathrm{C}$ & $3 \mathrm{hr}$ & $0.48-1.35$ & 0.01 & - & - & {$[130]$} \\
\hline $\begin{array}{c}\text { Inconel } \\
718\end{array}$ & $150 \mathrm{MPa}$ & $1180^{\circ} \mathrm{C}$ & $3 \mathrm{hr}$ & 0.27 & 0.06 & $21 \pm 5$ & $34 \pm 3$ & {$[132]$} \\
\hline $\mathrm{CMSX}-4$ & $100 \mathrm{MPa}$ & $1300^{\circ} \mathrm{C}$ & $4 \mathrm{~min}$ & 0.607 & 0.061 & - & - & {$[134]$} \\
\hline $\mathrm{CMSX}-4$ & $100 \mathrm{MPa}$ & $1315^{\circ} \mathrm{C}$ & $4 \mathrm{~min}$ & 0.607 & 0.074 & - & - & {$[134]$} \\
\hline Ti6Al4V & $100 \mathrm{MPa}$ & $920^{\circ} \mathrm{C}$ & $2 \mathrm{hr}$ & 0.97 & 0.10 & $13.6 \pm 1.4$ & $17.7 \pm 0.9$ & {$[138]$} \\
\hline $\begin{array}{c}\text { Inconel } \\
718\end{array}$ & $120 \mathrm{MPa}$ & $1200^{\circ} \mathrm{C}$ & $4 \mathrm{hr}$ & 0.70 & 0.05 & - & - & {$[135]$} \\
\hline
\end{tabular}

\subsection{MICROSTRUCTURE AND PROPERTIES}

Four alloy groups have seen significant utilization in metal AM to date [4], [143], [144]: titanium alloys [4], [145]-[147], stainless steels, Inconel alloys [45], [148], and aluminum alloys [149], [150]. Specific steel classes utilized in additive manufacturing include austenitic stainless steels [151], tool steels [152], precipitation hardenable stainless steels [153], and maraging steels [154]. General reviews on the hardness [155] of AM metals, the effect of build orientation [156], and anisotropic material properties [157] have been published. Key issues for each system are briefly reviewed in the following section; however, the study, prediction, and control of microstructure of metal AM processes encompasses a vast field of research due to the high number of combinations of processing methods and alloy designs.

Additively manufactured metallic components have comparable if not superior properties to conventionally manufactured parts, partially due to finer grain size [4]. PBF essentially welds layers together and the small $(50-500 \mu \mathrm{m})$ spot size of the energy source results in small melt pools and rapid cooling, which inhibits grain growth upon solidification. Columnar grain structures oriented lengthwise in the build direction (Zaxis) are frequently observed in PBF, and this grain structure has been reported in Ti6Al4V fabricated by SLM [158], EBM [159], and L-DED [160] as well as in Inconel 718 produced by SLM [9], [13], [161], EBM [35], [162], and L-DED [36]. Grain structures are primarily dependent on the temperature gradient and solidification interface velocity and it is possible to selectively form columnar or equiaxed grains by varying the energy source power and scan speed [163].

A review of the tensile properties of additively manufactured Ti6Al4V has been conducted [10], [164] and a number of articles have been published on the subject [165]-[172]. In general, the reported Young's modulus, yield strength, and ultimate tensile strength of PBF Ti6Al4V are comparable to wrought Ti6Al4V while reported ductility varied significantly. Reviews of Ti alloy fatigue behavior [173] reveal strong relationships between fatigue strength and the method of powder production. Ti and its alloys are highly reactive with oxygen and processes that form powder in a vacuum, such as PREP, result in lower oxide content powders. SLM of Ti forms a martensite phase with decreased ductility due to rapid solidification and cooling and, as a result, stress relief and phase transformation heat treatments are typically required for components with cyclical stress loads [174]. It has been reported, however, that careful SLM parameter choice can produce as-fabricated Ti6A14V without martensite [175]. EBM processes operate at temperatures high enough to facilitate in-situ stress relief and martensite phase transformation and so, postprocessing heat treatments are not required. Similarly, in L-DED, tensile yield and ultimate strengths are commensurate with wrought properties, with ductility approaching wrought properties with reduction in 
porosity [160]. Properties show anisotropy based on build direction due to prior $\beta$ grain columnar morphology.

Commonly used Ni alloys in AM include Inconel 718, Inconel 625, and Invar 36. The former two alloys are used in the aerospace industry due to strength retention at high temperatures [176]. Mechanical properties of Ni-based alloys have previously been reviewed and are listed in Table 2 [75]. While clear relationships between transverse and longitudinal ductility or UTS and ductility for PBF Ni alloys have not been reported, an expression has been developed [177] for estimating hardness given the elemental composition of a $\mathrm{Ni}$ alloy as shown in equation 1 [178]. Experimental results of hardness versus $\mathrm{Ni}$ equivalent are plotted in Figure 16 [75]. Comparable hardness analysis for aluminum and steel alloys have been conducted [177].

$\varphi=$

$\begin{aligned} \mathrm{Ni}+0.65 \mathrm{Cr} & +0.98 \mathrm{Mo}+1.05 \mathrm{Mn}+0.35 \mathrm{Si}+12.6 \mathrm{C}-6.36 \mathrm{Al}+3.80 \mathrm{~B}+0.01 \mathrm{Co}+0.26 \mathrm{Fe}+7.06 \mathrm{Hf} \\ & +1.20 \mathrm{Nb}+4.95 \mathrm{Ta}+5.78 \mathrm{Ti}+2.88 \mathrm{~W}\end{aligned}$

Austenitic stainless-steel alloys, particularly 316,316L, 304, and 304L, have seen considerable research in metal AM systems. All four alloys form delta ferrite and gamma austenite [179], [180] as predicted by the relevant phase diagram in Figure 17 [181]. Residual ferrite can be post-processed to austenite with solution heat treatments between $850^{\circ} \mathrm{C}$ and $1250^{\circ} \mathrm{C}$ [181], [182], which is desirable for NPP applications as ferrite is a thermodynamically unstable phase, susceptible to void swelling under radiation damage, and a major contributor to alloy embrittlement [182], [183]. Ferrite decomposes to $\sigma$ phase, a brittle intermetallic, and austenite upon aging. $\sigma$ phase is undesirable not only due to brittleness but also because it reduces grain boundary $\mathrm{Cr}$ content in the remaining austenite. Low $\mathrm{Cr}$ grain boundaries then act as nucleation sites for stress corrosion cracking. Experimental results indicate that irradiation-assisted stress corrosion cracking can be reduced via reduction in grain size [184]; therefore, heat treatments should be kept as brief and lowtemperature as possible to minimize grain growth. One additional consideration for metal AM stainless materials is that the presence of a small amount of oxygen forms disperse oxide precipitation in the matrix, which alters grain growth and hardness evolution during tempering [185]. One study of SLM SS316L reported to have achieved significantly smaller grain sizes $(5-16 \mu \mathrm{m}$ versus $50 \mu \mathrm{m})$ relative to conventional $\mathrm{SS} 316 \mathrm{~L}$ when solution heat treated at $1100^{\circ} \mathrm{C}$ for 1 hour [186]. As a result, SLM components may have comparatively high yield and tensile strengths due to grain size refinement even though not hot worked; higher dislocation densities due to rapid solidification and residual stress also affect material properties [179], [187]-[189]. 


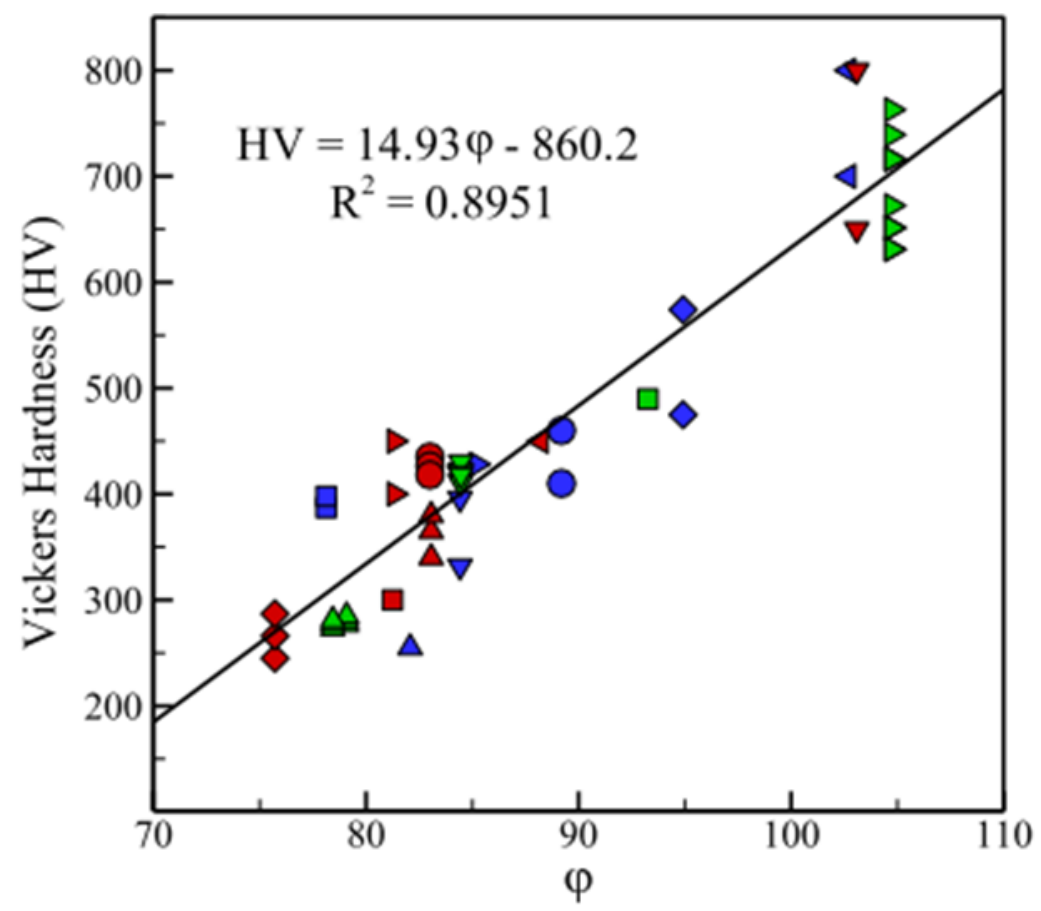

Figure 16: As-deposited HV as a function of Nickel equivalent [75].

Work on the mechanical properties [190]-[196] and fatigue characterization [197]-[199] of metal AM austenitic stainless steels produced by various fabrication parameters have been reported. However, meaningful comparison of results is complicated by the significant number of fabrication parameter variables and incomplete reporting in literature. Absorptivity of $\mathrm{Fe}$ varies from 0.12 at room temperature for a $\mathrm{CO}_{2}$ laser to $0.25-0.32$ for a Nd:YAG laser [200]. Therefore, it is necessary to report both applied power and laser wavelength in order to calculate absorbed energy, yet laser type is not consistently reported. Similarly, spot size, hatch spacing, layer thickness, build orientation, and material porosity are not consistently reported yet are required for accurate parameter comparison and calculation of thermal history. In general, austenitic stainless steels fabricated by PBF show slight anisotropy in material properties, and elongated grains and dendrites oriented in the Z-axis are often observed [180], [187], [188], [196], [201]. Yield strength and UTS are often higher than in conventionally annealed austenitic stainless steels while elongation at failure is decreased. It is not clear whether the decreased ductility is due to porosity and internal defects or smaller grains leading to dislocation buildup at grain boundaries [180], [187], [191], [192]. 
Table 2: Summary of mechanical properties of Ni-base alloys fabricated by AM in literature, compared to traditionally processed counterparts, where HT=heat treated [75].

\begin{tabular}{|c|c|c|c|c|c|c|c|c|c|c|}
\hline Alloy & $P(\mathrm{~W})$ & $v(\mathrm{~mm} / \mathrm{s})$ & $H(\mathrm{~J} / \mathrm{mm})$ & & Orientation & $E(\mathrm{GPa})$ & $\sigma_{y}(\mathrm{MPa})$ & $\sigma_{\text {uts }}(\mathrm{MPa})$ & Elongation (\%) & $\mathrm{HV}$ \\
\hline \multicolumn{11}{|c|}{$\begin{array}{l}\text { Powder bed fusion - } \\
\text { laser heat source }\end{array}$} \\
\hline \multirow[t]{3}{*}{ Invar 36} & 400 & $1800-4300$ & 0.22 & As-deposited & Long. & & 400 & 535 & 14 & \\
\hline & & & & & Transv. & & 340 & 455 & 30 & \\
\hline & & & & $\mathrm{HT}$ & Long. & & 311 & 447 & 32 & \\
\hline \multirow[t]{2}{*}{ Inconel 625} & 200 & $800-1200$ & 0.25 & HIP & Long. & & 380 & 900 & 58 & 347 \\
\hline & & & & & Transv. & & 360 & 880 & 58 & 296 \\
\hline \multirow{2}{*}{ Inconel 625} & 50 & 130 & 0.38 & As-deposited & Long. & $202.24 \pm 4.12$ & $800 \pm 20$ & $1030 \pm 50$ & $8-10$ & \\
\hline & & & & & Transv. & $140.66 \pm 8.67$ & $1070 \pm 60$ & $720 \pm 30$ & $8-10$ & \\
\hline \multirow[t]{2}{*}{ Haynes 230} & 200 & $450-1200$ & 0.44 & As-deposited & Long. & $205 \pm 4$ & $798 \pm 5$ & $1102 \pm 6$ & $28 \pm 1$ & \\
\hline & & & & & Transv. & $152 \pm 1$ & $656 \pm 4$ & $941 \pm 2$ & $32 \pm 3$ & \\
\hline \multicolumn{11}{|c|}{$\begin{array}{l}\text { Powder bed fusion - } \\
\quad \text { electron beam heat source }\end{array}$} \\
\hline \multirow[t]{2}{*}{ Inconel 625} & 1800 & $10^{4}$ & 0.18 & As-deposited & Transv. & & 410 & 750 & 44 & 224 \\
\hline & & & & HIP & Transv. & & 330 & 770 & 69 & \\
\hline \multicolumn{11}{|c|}{$\begin{array}{l}\text { Directed energy deposition - } \\
\text { powder feedstock }\end{array}$} \\
\hline \multirow[t]{3}{*}{ Inconel 718} & - & - & - & As-deposited & Long. & & 650 & 1000 & $38 \%$ (Reduction in area) & \\
\hline & & & & HT & Long. & & 1257 & 1436 & $13 \%$ (Reduction in area) & \\
\hline & & & & $\mathrm{HT}+\mathrm{HIP}$ & Long. & & 1155 & 1380 & $20.4 \%$ (Reduction in area) & \\
\hline \multirow{3}{*}{ Inconel 718} & 2350 & 8 & 294 & As-deposited & Long. & & 590 & 845 & 11 & \\
\hline & & & & $\mathrm{HT}$ & Long. & & 1133 & 1240 & 9 & \\
\hline & & & & & Long. & & 1170 & 1360 & 18 & \\
\hline \multicolumn{11}{|c|}{$\begin{array}{l}\text { Directed energy deposition - } \\
\quad \text { wire feedstock }\end{array}$} \\
\hline \multirow[t]{2}{*}{ Inconel 625} & & 5 & & As-deposited & Long. & 180 & & $722 \pm 17$ & $42.27 \pm 2.4$ & $240-270$ \\
\hline & & & & & Transv. & & & $684 \pm 23$ & $40.13 \pm 3.7$ & \\
\hline Inconel 718 & & 5 & & As-deposited & Long. & $154 \pm 1$ & $473 \pm 6$ & $828 \pm 8$ & $28 \pm 2$ & \\
\hline \multirow{3}{*}{ Inconel 718} & & & & As-deposited & Long. & 163 & 666 & 1022 & 26.1 & \\
\hline & & & & $\mathrm{HT}$ & Long. & 24.1 & 947 & 1242 & 23.5 & \\
\hline & & & & HT & Long. & 25.8 & 932 & 942 & 22.2 & \\
\hline \multicolumn{11}{|c|}{ Traditionally processed } \\
\hline \multirow[t]{2}{*}{ Inconel 718} & Cast - typical & & & & & & 915 & 1090 & 11 & 266 (max) \\
\hline & $\begin{array}{l}\text { Annealed and Aged - } \\
\text { minimum }\end{array}$ & & & & & & 862 & 1034 & 20 & 318 \\
\hline \multirow{2}{*}{ Inconel 625} & Cast - typical & & & & & & 350 & 710 & 48 & 266 (max) \\
\hline & Annealed - typical & & & & & & 430 & 940 & 51.5 & $145(\mathrm{~min})$ \\
\hline \multirow[t]{2}{*}{ Invar 36} & Cast - typical & & & & & & 265 & 483 & 44 & - \\
\hline & Annealed - typical & & & & & & 260 & 470 & 37 & 131 \\
\hline
\end{tabular}




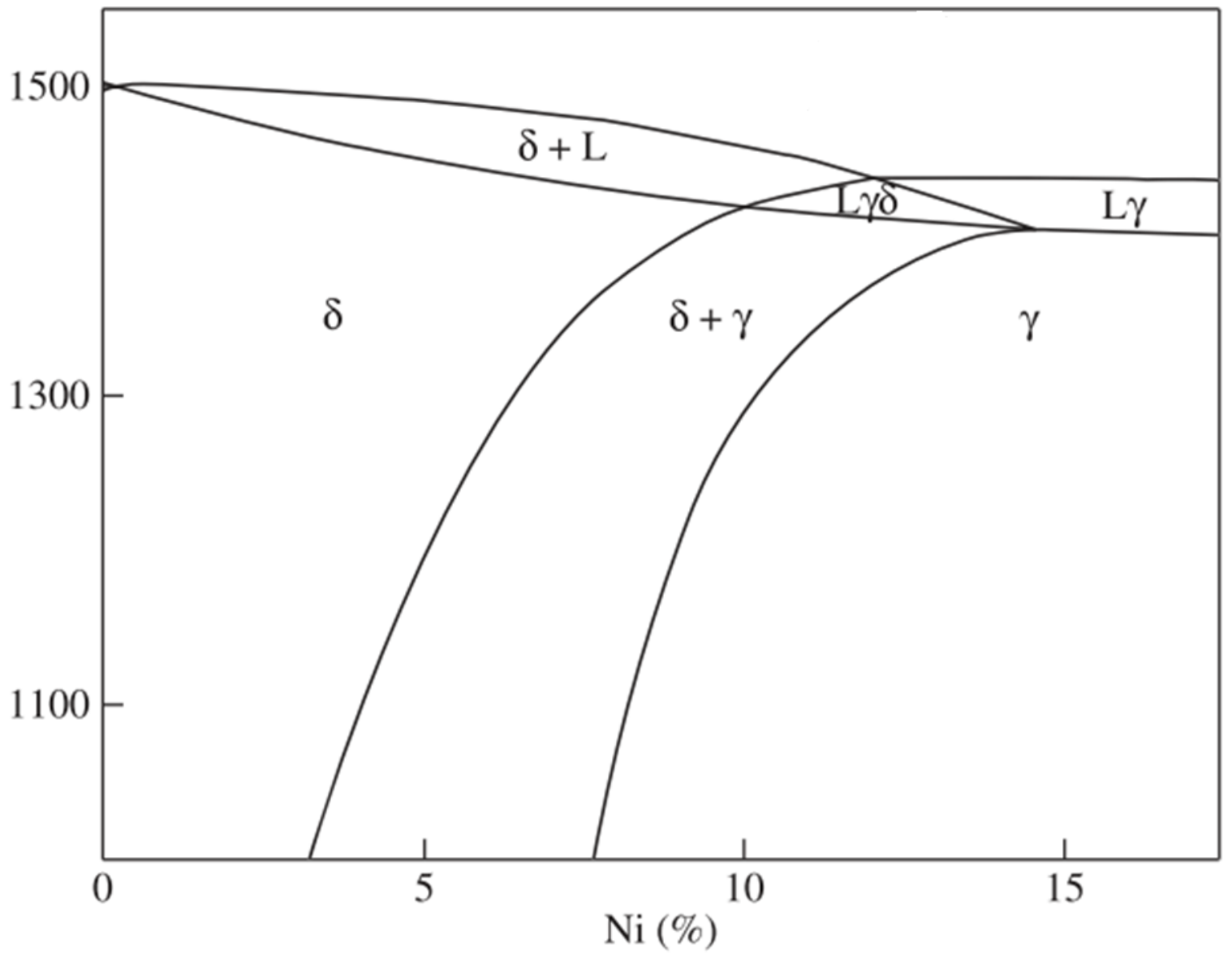

Figure 17: Phase diagram for 18wt\% Cr austenitic stainless steels [181]

\section{Acknowledgements}

The authors would like to thank Olivia Shafer for assistance in formatting and editing this manuscript. Research sponsored by the U.S. Department of Energy, Office of Energy Efficiency and Renewable Energy, Advanced Manufacturing Office, under contract DE-AC05-00OR22725 with UT-Battelle, LLC. 



\section{REFERENCES}

[1] “Boeing 787." [Online]. Available: https://www.reuters.com/article/us-norsk-boeingidUSKBN17C264. [Accessed: 18-Mar-2019].

[2] "Boeing SES-15." [Online]. Available: https://www.boeing.com/features/innovationquarterly/nov2017/feature-thought-leadership-3d-printing.page. [Accessed: 18-Mar-2019].

[3] “GE Fuel Nozzel.” [Online]. Available: https://www.ge.com/reports/epiphany-disruption-geadditive-chief-explains-3d-printing-will-upend-manufacturing/. [Accessed: 18-Mar-2019].

[4] D. Herzog, V. Seyda, E. Wycisk, and C. Emmelmann, "Additive manufacturing of metals," Acta Mater., vol. 117, pp. 371-392, 2016.

[5] W. E. Frazier, "Metal additive manufacturing: A review," J. Mater. Eng. Perform., vol. 23, no. 6, pp. 1917-1928, 2014.

[6] D. I. Wimpenny, P. M. Pandey, and L. J. Kumar, Eds., Advances in 3D Printing and Additive Manufacturing Technologies. Springer US, 2017.

[7] G. Allaire, C. Dapogny, R. Estevez, A. Faure, and G. Michailidis, "Structural optimization under overhang constraints imposed by additive manufacturing technologies," J. Comput. Phys., vol. 351, pp. 295-328, 2017.

[8] W. J. Sames, F. A. List, S. Pannala, R. R. Dehoff, and S. S. Babu, "The metallurgy and processing science of metal additive manufacturing," Int. Mater. Rev., vol. 61, no. 5, pp. 315-360, 2016.

[9] K. N. Amato et al., "Microstructures and mechanical behavior of Inconel 718 fabricated by selective laser melting," Acta Mater., vol. 60, pp. 2229-2239, 2012.

[10] Y. Zhang et al., "Additive Manufacturing of Metallic Materials: A Review," J. Mater. Eng. Perform., vol. 27, no. 1, pp. 1-13, 2018.

[11] W. J. Sames, K. A. Unocic, R. R. Dehoff, T. Lolla, and S. S. Babu, "Thermal effects on microstructural heterogeneity of Inconel 718 materials fabricated by electron beam melting," $J$. Mater. Res., vol. 29, no. 17, pp. 1920-1930, 2014.

[12] J. Karlsson, A. Snis, H. Engqvist, and J. Lausmaa, "Characterization and comparison of materials produced by Electron Beam Melting (EBM) of two different Ti-6Al-4V powder fractions," $J$. Mater. Process. Technol., vol. 213, pp. 2109-2118, 2013.

[13] L. M. Sochalski-Kolbus et al., "Comparison of Residual Stresses in Inconel 718 Simple Parts Made by Electron Beam Melting and Direct Laser Metal Sintering," Metall. Mater. Trans. A Phys. Metall. Mater. Sci., vol. 46A, pp. 1419-1432, 2015.

[14] B. Song, S. Dong, Q. Liu, H. Liao, and C. Coddet, "Vacuum heat treatment of iron parts produced by selective laser melting: Microstructure, residual stress and tensile behavior," Mater. Des., vol. 54, pp. 727-733, 2014.

[15] "ExOne Metal 3D Printing Process," ExOne, 2014. .

[16] I. Gibson, D. Rosen, and B. Stucker, "Binder Jetting," in Additive Manufacturing Technologies, 2015, pp. 205-218.

[17] M. Doyle, K. Agarwal, W. Sealy, and K. Schull, "Effect of Layer Thickness and Orientation on Mechanical Behavior of Binder Jet Stainless Steel 420 + Bronze Parts," Procedia Manuf., vol. 1, pp. 251-262, 2015.

[18] M. Ziaee, E. M. Tridas, and N. B. Crane, "Binder-Jet Printing of Fine Stainless Steel Powder with Varied Final Density," JOM, vol. 69, no. 3, pp. 592-596, 2017.

[19] T. Koslow, "Interview With Digital Metal: One Giant Leap For Small Metal 3D Printed Parts," All3DP, 2017. .

[20] S. K. Kennedy, A. M. Dalley, and G. J. Kotyk, “Additive Manufacturing: Assessing Metal Powder 
Quality Through Characterizing Feedstock and Contaminants," J. Mater. Eng. Perform., vol. 28, pp. 728-740, 2019.

[21] A. Santomaso, P. Lazzaro, and P. Canu, "Powder flowability and density ratios: The impact of granules packing," Chem. Eng. Sci., vol. 58, pp. 2857-2874, 2003.

[22] A. T. Sutton, C. S. Kriewall, M. C. Leu, and J. W. Newkirk, "Powder characterisation techniques and effects of powder characteristics on part properties in powder-bed fusion processes," Virtual Phys. Prototyp., vol. 12, no. 1, pp. 3-29, 2016.

[23] J. Lei, J. Xie, S. Zhou, H. Song, X. Song, and X. Zhou, "Comparative study on microstructure and corrosion performance of 316 stainless steel prepared by laser melting deposition with ring-shaped beam and Gaussian beam," Opt. Laser Technol., vol. 111, pp. 271-283, 2019.

[24] A. Klassen, T. Scharowsky, and C. Körner, "Evaporation model for beam based additive manufacturing using free surface lattice Boltzmann methods," J. Phys. D. Appl. Phys., vol. 47, 2014.

[25] A. Klassen, V. E. Forster, and C. Körner, "A multi-component evaporation model for beam melting processes," Model. Simul. Mater. Sci. Eng., vol. 25, 2017.

[26] H. P. Tang, M. Qian, N. Liu, X. Z. Zhang, G. Y. Yang, and J. Wang, "Effect of Powder Reuse Times on Additive Manufacturing of Ti-6Al-4V by Selective Electron Beam Melting," Jom, vol. 67, no. 3, pp. 555-563, 2015.

[27] G. Jacob, C. Brown, A. Donmez, S. Watson, and J. Slotwinski, "Effects of powder recycling on stainless steel powder and built material properties in metal powder bed fusion processes," NIST Adv. Manuf. Ser., vol. 100-6, 2017.

[28] A. Simchi, "The role of particle size on the laser sintering of iron powder," Metall. Mater. Trans. B Process Metall. Mater. Process. Sci., vol. 35B, pp. 937-948, 2004.

[29] D. Manfredi, F. Calignano, M. Krishnan, R. Canali, E. P. Ambrosio, and E. Atzeni, "From powders to dense metal parts: Characterization of a commercial alsimg alloy processed through direct metal laser sintering," Materials (Basel)., vol. 6, pp. 856-869, 2013.

[30] J. A. Slotwinski, E. J. Garboczi, P. E. Stutzman, C. F. Ferraris, S. S. Watson, and M. A. Peltz, "Characterization of Metal Powders Used For Additive Manufacturing," J. Res. Natl. Inst. Stand. Technol., vol. 119, p. 460, 2014.

[31] ASTM-International, "Standard test methods for flow rate of metal powders using the Hall Flowmeter funnel,” B213-17th ed., West Conshohocken, PA: ASTM International, 2017.

[32] ASTM-International, "Standard test method for apparent density of free-flowing metal powders using the Hall Flowmeter funnel," B212-17th ed., West Conshohocken, PA: ASTM International, 2017.

[33] AP\&C, "Designed for additive manufacturing." [Online]. Available: http://advancedpowders.com/our-plasma-atomized-powders/designed-for-additive-manufacturing/. [Accessed: 18-Mar-2019].

[34] R. H. Bochuan Liu, Ricky Wildman, Christopher Tuck, Ian Ashcroft, "INVESTIGATION THE EFFECT OF PARTICLE SIZE DISTRIBUTION ON PROCESSING PARAMETERS OPTIMISATION IN SELECTIVE LASER MELTING PROCESS," in 22nd Annual International Solid Freeform Fabrication Symposium - An Additive Manufacturing Conference, 2011.

[35] W. J. Sames, F. Medina, W. H. Peter, S. S. Babu, and R. R. Dehoff, "Effect of Process Control and Powder Quality on Inconel 718 Produced Using Electron Beam Melting," 8th Int. Symp. Superalloy 718 Deriv., pp. 409-423, 2014.

[36] H. Qi, M. Azer, and A. Ritter, "Studies of standard heat treatment effects on microstructure and mechanical properties of laser net shape manufactured INCONEL 718," Metall. Mater. Trans. A Phys. Metall. Mater. Sci., vol. 40A, pp. 2410-2422, 2009.

[37] X. Zhao, J. Chen, X. Lin, and W. Huang, "Study on microstructure and mechanical properties of laser rapid forming Inconel 718," Mater. Sci. Eng. A, vol. 478, no. 1-2, pp. 119-124, 2008.

[38] F. Medina, "Reducing Metal Alloy Powder Costs for Use in Powder Bed Fusion Additive Manufacturing: Improving the Economics for Production," University of Texas at El Paso, 2013. 
[39] P. A. Kobryn, E. H. Moore, and S. L. Semiatin, "Effect of laser power and traverse speed on microstructure, porosity, and build height in laser-deposited Ti-6Al-4V," Scr. Mater., vol. 43, pp. 299-305, 2000.

[40] J. Robinson, I. Ashton, P. Fox, E. Jones, and C. Sutcliffe, "Determination of the effect of scan strategy on residual stress in laser powder bed fusion additive manufacturing," Addit. Manuf., vol. 23, pp. 13-24, 2018.

[41] L. N. Carter, M. M. Attallah, and R. C. Reed, "Laser powder bed fabrication of nickel-base superalloys: influence of parameters; characterisation, quantification and mitigation of cracking," in Superalloys 2012: 12th International Symposium on Superalloys, 2012, pp. 577--586.

[42] "GE Unveils First Beta Machine from Project ATLAS Program," 2017. .

[43] A. Hussein, L. Hao, C. Yan, R. Everson, and P. Young, "Advanced lattice support structures for metal additive manufacturing," J. Mater. Process. Technol., vol. 213, pp. 1019-1026, 2013.

[44] J. Cao, F. Liu, X. Lin, C. Huang, J. Chen, and W. Huang, "Effect of overlap rate on recrystallization behaviors of Laser Solid Formed Inconel 718 superalloy," Opt. Laser Technol., vol. 45, pp. 228-235, 2013.

[45] C. Körner, H. Helmer, A. Bauereiß, and R. F. Singer, "Tailoring the grain structure of IN718 during selective electron beam melting," MATEC Web Conf., vol. 14, 2014.

[46] J. D. Hunt, "Steady state columnar and equiaxed growth of dendrites and eutectic," Mater. Sci. Eng., vol. 65, pp. 75-83, 1984.

[47] L. Nastac, J. J. Valencia, M. L. Tims, and F. R. Dax, "Advances in the Solidification of IN718 and RS5 Alloys," in TMS, 2001, pp. 103-112.

[48] Joy Gockel and Jack Beuth, "Understanding Ti-6Al-4V Microstructure Control in Additive Manufacturing via Process Maps," in 24th International SFF Symposium - An Additive Manufacturing Conference, 2013, pp. 666-674.

[49] X. Wang, M. Jiang, Z. Zhou, J. Gou, and D. Hui, "3D printing of polymer matrix composites: A review and prospective," Compos. Part B Eng., vol. 110, pp. 442-458, 2017.

[50] "Functionally graded material of 304L stainless steel and inconel 625 fabricated by directed energy deposition: Characterization and thermodynamic modeling," Acta Mater., vol. 108, pp. 46 54, 2016.

[51] D. C. H. et Al, "Compositionally graded metals: A new frontier of additive manufacturing," $J$. Mater. Res., vol. 29, no. 17, pp. 1899-1910, 2014.

[52] D. Kong, "High-throughput fabrication of nickel-based alloys with different $\mathrm{Nb}$ contents via a dual-feed additive manufacturing system: Effect of $\mathrm{Nb}$ content on microstructural and mechanical properties," J. Alloys Compd., vol. 785, pp. 826-837, 2019.

[53] M. K. Thompson et al., "Design for Additive Manufacturing: Trends, opportunities, considerations, and constraints," CIRP Ann., vol. 65, no. 2, pp. 737-760, 2016.

[54] A. Elliott and C. Waters, Additive Manufacturing for Designers: A Primer. SAE International, 2019.

[55] B. A. Varotsis, "How to design parts for Binder Jetting 3D printing," 3D Hubs, 2018. .

[56] L. Kempen, L. Thijs, B. Vrancken, S. Buls, J. Van Humbeeck, and J.-P. Kruth, "Producing crackfree, high density M2 HSS parts by Selective Laser Melting: Pre-heating the baseplate," Proc. 24th Int. solid Free. Fabr. Symp., pp. 131-139, 2013.

[57] S. Kou, Welding Metallurgy, 2nd ed. Hoboken, New Jersey: John Wiley and Sons, 2003.

[58] T. Mukherjee, W. Zhang, and T. DebRoy, "An improved prediction of residual stresses and distortion in additive manufacturing," Comput. Mater. Sci., vol. 126, pp. 360-372, 2017.

[59] P. Mercelis and J.-P. Kruth, "Residual stresses in Selective Laser Sintering and Selective Laser Melting," 16th Solid Free. Fabr. Symp. SFF 2005, vol. 12, pp. 109-131, 2005.

[60] A. Wu, M. M. LeBlanc, M. Kumar, G. F. Gallegos, D. W. Brown, and W. E. King, "Effect of laser scanning pattern and build direction in additive manufacturing on anisotropy, porosity and residual stress," in 2014 TMS annual meeting \& exhibition, 2014.

[61] G. K. Lewis and E. Schlienger, "Practical considerations and capabilities for laer assisted direct 
metal deposition," Mater. Des., vol. 21, pp. 417-423, 2000.

[62] T. Gnäupel-Herold, J. Slotwinski, and S. Moylan, "Neutron measurements of stresses in a test artifact produced by laser-based additive manufacturing," in AIP Conference Proceedings, 2014, vol. 1581, pp. 1205-1212.

[63] P. Rangaswamy, T. M Holden, R. Rogge, and M. L Griffith, "Residual stresses in components formed by the laser-engineered net shaping (LENS (R)) process," J. Strain Anal. Eng. Des., vol. 38, 2003.

[64] C. A. Brice and W. H. Hofmeister, "Determination of bulk residual stresses in electron beam additive-manufactured aluminum," Metall. Mater. Trans. A Phys. Metall. Mater. Sci., vol. 44A, pp. 5147-5153, 2013.

[65] A. S. Wu, D. W. Brown, M. Kumar, G. F. Gallegos, and W. E. King, “An Experimental Investigation into Additive Manufacturing-Induced Residual Stresses in 316L Stainless Steel," Metall. Mater. Trans. A Phys. Metall. Mater. Sci., vol. 45A, pp. 6260-6270, 2014.

[66] T. Watkins et al., "Neutron Characterization for Additive Manufacturing," Adv. Mater. Process., vol. 171, no. 3, pp. 23-27, 2013.

[67] P. Rangaswamy et al., "Residual stresses in LENS ${ }^{\circledR}$ components using neutron diffraction and contour method," Mater. Sci. Eng. A, vol. 399, pp. 72-83, 2005.

[68] J. M. Robinson, B. A. Van Brussel, J. T. M. De Hosson, and R. C. Reed, "X-ray measurement of residual stresses in laser surface melted Ti-6Al-4V alloy," Mater. Sci. Eng. A, vol. 208, pp. 143147, 1996.

[69] M. B. Prime, "Cross-Sectional Mapping of Residual Stresses by Measuring the Surface Contour After a Cut," J. Eng. Mater. Technol., vol. 123, p. 162, 2001.

[70] S. Suresh and A. E. Giannakopoulos, "A new method for estimating residual stresses by instrumented sharp indentation," Acta Mater., vol. 46, no. 16, pp. 5755-5767, 1998.

[71] M. . Griffith et al., "Understanding thermal behavior in the LENS process," Mater. Des., vol. 20, pp. 107-113, 1999.

[72] R. J. Moat, A. J. Pinkerton, L. Li, P. J. Withers, and M. Preuss, "Residual stresses in laser direct metal deposited Waspaloy," Mater. Sci. Eng. A, vol. 528, no. 6, pp. 2288-2298, 2011.

[73] M. F. Zaeh and G. Branner, "Investigations on residual stresses and deformations in selective laser melting," Prod. Eng., vol. 4, pp. 35-45, 2010.

[74] P. Prabhakar, W. J. Sames, R. Dehoff, and S. S. Babu, "Computational modeling of residual stress formation during the electron beam melting process for Inconel 718," Addit. Manuf., vol. 7, pp. 83-91, 2015.

[75] T. DebRoy et al., "Additive manufacturing of metallic components - Process, structure and properties," Prog. Mater. Sci., vol. 92, pp. 112-224, 2018.

[76] D. Dye, O. Hunziker, and R. C. Reed, "Numerical analysis of the weldability of superalloys," Acta Mater., vol. 49, pp. 683-697, 2001.

[77] M. F. Zäh and S. Lutzmann, "Modelling and simulation of electron beam melting," Prod. Eng., vol. 4, pp. 15-23, 2010.

[78] A. V. Gusarov, I. Yadroitsev, P. Bertrand, and I. Smurov, "Heat transfer modelling and stability analysis of selective laser melting," Appl. Surf. Sci., vol. 254, pp. 975-979, 2007.

[79] M. F. Zaeh and M. Kahnert, "The effect of scanning strategies on electron beam sintering," Prod. Eng., vol. 3, pp. 217-224, 2009.

[80] M. Kahnert, S. Lutzmann, and M. F. Zaeh, "Layer formations in electron beam sintering," Proc. 18th Solid Free. Fabr. Symp., pp. 88-99, 2007.

[81] T. D. McLouth et al., "The effect of laser focus shift on microstructural variation of Inconel 718 produced by selective laser melting," Mater. Des., vol. 149, pp. 205-213, 2018.

[82] H. E. Helmer, C. Körner, and R. F. Singer, "Additive manufacturing of nickel-based superalloy Inconel 718 by selective electron beam melting: Processing window and microstructure," J. Mater. Res., vol. 29, no. 17, pp. 1987-1996, 2014.

[83] V. D. Manvatkar et al., "Estimation of Melt Pool Dimensions, Thermal Cycle, and Hardness 
Distribution in the Laser-Engineered Net Shaping Process of Austenitic Stainless Steel," Metall. Mater. Trans. A, vol. 42A, no. 13, pp. 4080-4087, 2011.

[84] K. T. Makiewicz, "Development of simultaneous transformation kinetics microstructure model with application to laser metal deposited Ti-6Al-4V and alloy 718," 2013.

[85] J. C. Haley, B. Zheng, U. S. Bertoli, A. D. Dupuy, J. M. Schoenung, and E. J. Lavernia, "Working distance passive stability in laser directed energy deposition additive manufacturing," Mater. Des., 2019.

[86] K. T. Makiewicz, "Development of simultaneous transformation kinetics microstructure model with application to laser metal deposited Ti-6Al-4V and alloy 718," Ohio State Univ., p. 259, 2013.

[87] R. Quarshie, S. Machachlan, P. Reeves, D. Whittaker, and R. Blake, "Shaping Our National Competency in Additive Manufacturing," 2012.

[88] NIST, "Measurement Science Roadmap for Metal-Based Additive Manufacturing," p. 86, 2013.

[89] M. Van Elsen, "Complexity of Selective Laser Melting: a new optimisation approach," KATHOLIEKE UNIVERSITEIT LEUVEN, 2007.

[90] S. K. Everton, M. Hirsch, P. I. Stavroulakis, R. K. Leach, and A. T. Clare, "Review of in-situ process monitoring and in-situ metrology for metal additive manufacturing," Mater. Des., vol. 95, pp. 431-445, 2016.

[91] G. Tapia and A. Elwany, "A Review on Process Monitoring and Control in Metal-Based Additive Manufacturing," J. Manuf. Sci. Eng., vol. 136, 2014.

[92] S. Berumen, F. Bechmann, S. Lindner, J. P. Kruth, and T. Craeghs, "Quality control of laser- and powder bed-based Additive Manufacturing (AM) technologies," Phys. Procedia, vol. 5, pp. 617622, 2010.

[93] F. Herzog, F. Bechmann, S. Berumen, J.P. Kruth, and T. Craeghs, "Method for Producing a ThreeDimensional Component," WO1996008749 A3, 1995.

[94] A. Fathi, E. Toyserkani, A. Khajepour, and M. Durali, "Prediction of melt pool depth and dilution in laser powder deposition," J. Phys. D. Appl. Phys., vol. 39, pp. 2613-2623, 2006.

[95] M. Mani, B. M. Lane, M. A. Donmez, S. C. Feng, and S. P. Moylan, "A review on measurement science needs for real-time control of additive manufacturing metal powder bed fusion processes," Int. J. Prod. Res., vol. 55, no. 5, pp. 1400-1418, 2017.

[96] A. Fathi, A. Khajepour, M. Durali, and E. Toyserkani, "Geometry Control of the Deposited Layer in a Nonplanar Laser Cladding Process Using a Variable Structure Controller," J. Manuf. Sci. Eng., vol. 130, p. 031003, 2008.

[97] D. Salehi and M. Brandt, "Melt pool temperature control using LabVIEW in Nd:YAG laser blown powder cladding process," Int. J. Adv. Manuf. Technol., vol. 29, pp. 273-278, 2006.

[98] T. A. Davis and Y. C. Shin, "Vision-based clad height measurement," Mach. Vis. Appl., vol. 22, pp. 129-136, 2011.

[99] E. Rodriguez, J. Mireles, C. A. Terrazas, D. Espalin, M. A. Perez, and R. B. Wicker, "Approximation of absolute surface temperature measurements of powder bed fusion additive manufacturing technology using in situ infrared thermography," Addit. Manuf., vol. 5, pp. 31-39, 2015.

[100] G. Bi, C. N. Sun, and A. Gasser, "Study on influential factors for process monitoring and control in laser aided additive manufacturing," J. Mater. Process. Technol., vol. 213, pp. 463-468, 2013.

[101] M. Islam, T. Purtonen, H. Piili, A. Salminen, and O. Nyrhilä, "Temperature profile and imaging analysis of laser additive manufacturing of stainless steel," Phys. Procedia, vol. 41, pp. 835-842, 2013.

[102] S. Barua, F. Liou, J. Newkirk, and T. Sparks, "Vision-based defect detection in laser metal deposition process," Rapid Prototyp. J., vol. 20, no. 1, pp. 77-85, 2014.

[103] J. C. Heigel, P. Michaleris, and E. W. Reutzel, "Thermo-mechanical model development and validation of directed energy deposition additive manufacturing of Ti-6Al-4V," Addit. Manuf., vol. 5, pp. 9-19, 2015. 
[104] M. Zeinali and A. Khajepour, "Height Control in Laser Cladding Using Adaptive Sliding Mode Technique: Theory and Experiment," J. Manuf. Sci. Eng., vol. 132, p. 041016, 2010.

[105] L. Tang and R. G. Landers, "Melt Pool Temperature Control for Laser Metal Deposition Processes-Part I: Online Temperature Control," J. Manuf. Sci. Eng., vol. 132, pp. 011010-1, 2010.

[106] L. Tang and R. G. Landers, "Melt Pool Temperature Control for Laser Metal Deposition Processes-Part II: Layer-to-Layer Temperature Control," J. Manuf. Sci. Eng., vol. 132, p. $011011,2010$.

[107] E. R. Denlinger, "Residual Stress and Distortion Modeling of Electron Beam Direct Manufacturing Ti-6Al-4V," in Thermo-Mechanical Modeling of Additive Manufacturing, $\mathrm{M}$. Gouge and P. Michaleris, Eds. Butterworth-Heinemann, 2018, pp. 153-166.

[108] E. R. Denlinger, J. C. Heigel, P. Michaleris, and T. A. Palmer, "Effect of inter-layer dwell time on distortion and residual stress in additive manufacturing of titanium and nickel alloys," J. Mater. Process. Technol., vol. 215, pp. 123-131, 2015.

[109] A. J. Dunbar et al., "Development of experimental method for in situ distortion and temperature measurements during the laser powder bed fusion additive manufacturing process," Addit. Manuf., vol. 12, pp. 25-30, 2016.

[110] L. W. Koester, H. Taheri, T. A. Bigelow, P. C. Collins, and L. J. Bond, "Nondestructive Testing for Metal Parts Fabricated Using Powder-Based Additive Manufacturing," Mater. Eval., no. April, 2018.

[111] J. A. Slotwinski, E. J. Garboczi, and K. M. Hebenstreit, "Porosity Measurements and Analysis for Metal Additive Manufacturing Process Control," J. Res. Natl. Inst. Stand. Technol., vol. 119, p. 494, 2014.

[112] E. Girardin, C. Renghini, J. Dyson, V. Calbucci, F. Moroncini, and G. Albertini, "Characterization of Porosity in a Laser Sintered MMCp Using X-Ray Synchrotron Phase Contrast Microtomography," Mater. Sci. Appl., vol. 02, no. 09, pp. 1322-1330, 2011.

[113] J. W. Elmer, J. Vaja, and H. D. Carlton, "The effect of reduced pressure on laser keyhole weld porosity and weld geometry in commercially pure titanium and nickel," Weld. J. 94, vol. 95, pp. 419-430, 2016.

[114] J. W. Elmer, J. Vaja, H. D. Carlton, and R. Pong, "The Effect of Ar and N2 Shielding Gas on Laser Weld Porosity in Steel, Stainless Steel, and Nickel," Weld. J., vol. 94, pp. 313-325, 2015.

[115] W. E. King et al., "Observation of keyhole-mode laser melting in laser powder-bed fusion additive manufacturing," J. Mater. Process. Technol., vol. 214, pp. 2915-2925, 2014.

[116] L. L. Parimi, G. Ravi, D. Clark, and M. M. Attallah, "Microstructural and texture development in direct laser fabricated IN718," Mater. Charact., vol. 89, pp. 102-111, 2014.

[117] A. F. H. Kaplan and J. Powell, "Spatter in laser welding," J. Laser Appl., vol. 23, p. 032005, 2011.

[118] E. C. Santos, M. Shiomi, K. Osakada, and T. Laoui, "Rapid manufacturing of metal components by laser forming," Int. J. Mach. Tools Manuf., vol. 46, pp. 1459-1468, 2006.

[119] K. A. Mumtaz and N. Hopkinson, "Selective Laser Melting of thin wall parts using pulse shaping," J. Mater. Process. Technol., vol. 210, pp. 279-287, 2010.

[120] T. R. Mahale, "Electron Beam Melting of Advanced Materials and Structures," North Carolina State University, 2009.

[121] C. Eschey, S. Lutzmann, and M. F. Zaeh, "Examination of the powder spreading effect in Electron Beam Melting (EBM)," Proc. 20th Solid Free. Fabr. Symp., pp. 308-319, 2009.

[122] M. Picasso, C. F. Marsden, . D. Wagniere, A. Frenk, and M. Rappaz, "A simple but realistic model for laser cladding," MMTB, vol. 25, no. 2, pp. 281-291, 1994.

[123] J. C. Haley, J. M. Schoenung, and E. J. Lavernia, "Observations of particle-melt pool impact events in directed energy deposition," Addit. Manuf., vol. 22, pp. 368-374, 2018.

[124] X. Gong, T. Anderson, and K. Chou, "Review on Powder-Based Electron Beam Additive Manufacturing Technology," in ASME/ISCIE 2012 International Symposium on Flexible Automation, 2012. 
[125] P. L. Blackwell, "The mechanical and microstructural characteristics of laser-deposited IN718," $J$. Mater. Process. Technol., vol. 170, pp. 240-246, 2005.

[126] M. Seifi, A. A. Salem, D. P. Satko, R. Grylls, and J. J. Lewandowski, "Effects of Post-processing on Microstructure and Mechanical Properties of SLM-Processed IN-718," in Proceedings of the 9th International Symposium on Superalloy 718 \& Derivatives: Energy, Aerospace, and Industrial Applications, 2018, pp. 515-526.

[127] S. Goel, J. Olsson, M. Ahlfors, U. Klement, and S. Joshi, "The Effect of Location and Posttreatment on the Microstructure of EBM-Built Alloy 718," in Proceedings of the 9th International Symposium on Superalloy 718 \& Derivatives: Energy, Aerospace, and Industrial Applications, 2018, pp. 115-129.

[128] A. R. Balachandramurthi, J. Moverare, S. Mahade, and R. Pederson, "Additive manufacturing of alloy 718 via electron beam melting: Effect of post-treatment on the microstructure and the mechanical properties," Materials (Basel)., vol. 12, 2018.

[129] G. Marchese et al., "Microstructural Evolution of Post-Processed Hastelloy X Alloy Fabricated by Laser Powder Bed Fusion," Materials (Basel)., vol. 12, p. 486, 2019.

[130] K. Moussaoui, W. Rubio, M. Mousseigne, T. Sultan, and F. Rezai, "Effects of Selective Laser Melting additive manufacturing parameters of Inconel 718 on porosity, microstructure and mechanical properties," Mater. Sci. Eng. A, vol. 735, pp. 182-190, 2018.

[131] E. Sadeghi, P. Karimi, S. Momeni, M. Seifi, A. Eklund, and J. Andersson, "Influence of thermal post treatments on microstructure and oxidation behavior of EB-PBF manufactured Alloy 718," Mater. Charact., vol. 150, pp. 236-251, 2019.

[132] V. A. Popovich, E. V. Borisov, A. A. Popovich, V. S. Sufiiarov, D. V. Masaylo, and L. Alzina, "Impact of heat treatment on mechanical behaviour of Inconel 718 processed with tailored microstructure by selective laser melting," Mater. Des., vol. 131, pp. 12-22, 2017.

[133] A. Mostafa, I. Picazo Rubio, V. Brailovski, M. Jahazi, and M. Medraj, "Structure, Texture and Phases in 3D Printed IN718 Alloy Subjected to Homogenization and HIP Treatments," Metals (Basel)., vol. 7, 2017.

[134] B. Ruttert, M. Ramsperger, L. Mujica Roncery, I. Lopez-Galilea, C. Körner, and W. Theisen, "Impact of hot isostatic pressing on microstructures of CMSX-4 Ni-base superalloy fabricated by selective electron beam melting," Mater. Des., vol. 110, pp. 720-727, 2016.

[135] S. Goel, M. Ahlfors, F. Bahbou, and S. Joshi, "Effect of Different Post-treatments on the Microstructure of EBM-Built Alloy 718,” J. Mater. Eng. Perform., vol. 28, pp. 673-680, 2019.

[136] B. Shassere, D. Greeley, A. Okello, M. Kirka, P. Nandwana, and R. Dehoff, "Correlation of Microstructure to Creep Response of Hot Isostatically Pressed and Aged Electron Beam Melted Inconel 718," Metall. Mater. Trans. A Phys. Metall. Mater. Sci., vol. 49A, pp. 5107-5117, 2018.

[137] R. Wauthle et al., "Effects of build orientation and heat treatment on the microstructure and mechanical properties of selective laser melted Ti6Al4V lattice structures," Addit. Manuf., vol. 5, pp. 77-84, 2015.

[138] S. L. Lu, H. P. Tang, Y. P. Ning, N. Liu, D. H. StJohn, and M. Qian, "Microstructure and Mechanical Properties of Long Ti-6Al-4V Rods Additively Manufactured by Selective Electron Beam Melting Out of a Deep Powder Bed and the Effect of Subsequent Hot Isostatic Pressing," Metall. Mater. Trans. A Phys. Metall. Mater. Sci., vol. 46A, pp. 3824-3834, 2015.

[139] N. Perevoshchikova, C. R. Hutchinson, and X. Wu, "The design of hot-isostatic pressing schemes for Ti-5Al-5Mo-5V-3Cr (Ti-5553)," Mater. Sci. Eng. A, vol. 657, pp. 371-382, 2016.

[140] A. B. Spierings, K. Dawson, K. Kern, F. Palm, and K. Wegener, "SLM-processed Sc- and Zrmodified Al-Mg alloy: Mechanical properties and microstructural effects of heat treatment," Mater. Sci. Eng. A, vol. 701, pp. 264-273, 2017.

[141] Y. Zhai, B. Huang, X. Mao, and M. Zheng, "Effect of hot isostatic pressing on microstructure and mechanical properties of CLAM steel produced by selective laser melting," J. Nucl. Mater., vol. 515, pp. 111-121, 2019.

[142] M. Åsberg, G. Fredriksson, S. Hatami, W. Fredriksson, and P. Krakhmalev, "Influence of post 
treatment on microstructure, porosity and mechanical properties of additive manufactured H13 tool steel," Mater. Sci. Eng. A, vol. 742, pp. 584-589, 2019.

[143] T. D. Ngo, A. Kashani, G. Imbalzano, K. T. Q. Nguyen, and D. Hui, "Additive manufacturing (3D printing): A review of materials, methods, applications and challenges," Compos. Part B Eng., vol. 143, pp. 172-196, 2018.

[144] D. D. Gu, W. Meiners, K. Wissenbach, and R. Poprawe, "Laser additive manufacturing of ceramic components: Materials, processes, and mechanisms," Int. Mater. Rev., vol. 57, no. 3, pp. 133-164, 2012.

[145] Y. Hu et al., "Laser deposition-additive manufacturing of in situ TiB reinforced titanium matrix composites: TiB growth and part performance," Int. J. Adv. Manuf. Technol., vol. 93, pp. 34093418, 2017.

[146] J. Vaithilingam, S. Kilsby, R. D. Goodridge, S. D. R. Christie, S. Edmondson, and R. J. M. Hague, "Functionalisation of Ti6A14V components fabricated using selective laser melting with a bioactive compound," Mater. Sci. Eng. C, vol. 46, pp. 52-61, 2015.

[147] H. Attar, M. Calin, L. C. Zhang, S. Scudino, and J. Eckert, "Manufacture by selective laser melting and mechanical behavior of commercially pure titanium," Mater. Sci. Eng. A, vol. 593, pp. 170-177, 2014.

[148] I. Yadroitsev, L. Thivillon, P. Bertrand, and I. Smurov, "Strategy of manufacturing components with designed internal structure by selective laser melting of metallic powder," Appl. Surf. Sci., vol. 254, pp. 980-983, 2007.

[149] I. Rosenthal, A. Stern, and N. Frage, "Strain rate sensitivity and fracture mechanism of AlSi10Mg parts produced by Selective Laser Melting," Mater. Sci. Eng. A, vol. 682, pp. 509-517, 2017.

[150] P. Vora, K. Mumtaz, I. Todd, and N. Hopkinson, "AlSi12 in-situ alloy formation and residual stress reduction using anchorless selective laser melting," Addit. Manuf., vol. 7, pp. 12-19, 2015.

[151] H. D. Carlton, A. Haboub, G. F. Gallegos, D. Y. Parkinson, and A. A. MacDowell, "Damage evolution and failure mechanisms in additively manufactured stainless steel," Mater. Sci. Eng. A, vol. 651, pp. 406-414, 2016.

[152] J. Mazumder, J. Choi, K. Nagarathnam, J. Koch, and D. Hetzner, "The Direct Metal Deposition of H13 Tool Steel for 3-D Components," JOM, vol. 49, no. 5, pp. 55-60, 1997.

[153] L. E. Murr et al., "Microstructures and properties of 17-4 PH stainless steel fabricated by selective laser melting," J. Mater. Res. Technol., vol. 1, no. 3, pp. 167-177, 2012.

[154] G. Casalino, S. L. Campanelli, N. Contuzzi, and A. D. Ludovico, "Experimental investigation and statistical optimisation of the selective laser melting process of a maraging steel," Opt. Laser Technol., vol. 65, pp. 151-158, 2015.

[155] J. S. Zuback and T. DebRoy, "The Hardness of Additively Manufactured Alloys," Materials (Basel)., vol. 11, p. 2070, 2018.

[156] S. Magar, N. K. Khedkar, and S. Kumar, "Review of the effect of built orientation on mechanical Properties of metal-plastic composite parts fabricated by Additive Manufacturing Technique," Mater. Today Proc., vol. 5, pp. 3926-3935, 2018.

[157] Y. Kok et al., "Anisotropy and heterogeneity of microstructure and mechanical properties in metal additive manufacturing: A critical review," Mater. Des., vol. 139, pp. 565-586, 2018.

[158] P. Edwards and M. Ramulu, "Fatigue performance evaluation of selective laser melted Ti-6Al4V," Mater. Sci. Eng. A, vol. 598, pp. 327-337, 2014.

[159] S. S. Al-Bermani, M. L. Blackmore, W. Zhang, and I. Todd, "The origin of microstructural diversity, texture, and mechanical properties in electron beam melted Ti-6Al-4V," Metall. Mater. Trans. A Phys. Metall. Mater. Sci., vol. 41A, pp. 3422-3434, 2010.

[160] B. E. Carroll, T. A. Palmer, and A. M. Beese, "Anisotropic tensile behavior of Ti-6Al-4V components fabricated with directed energy deposition additive manufacturing," Acta Mater., vol. 87, pp. 309-320, 2015.

[161] Z. Wang, K. Guan, M. Gao, X. Li, X. Chen, and X. Zeng, "The microstructure and mechanical properties of deposited-IN718 by selective laser melting," J. Alloys Compd., vol. 513, pp. 518- 
$523,2012$.

[162] K. A. Unocic, L. Kolbus, R. R. Dehoff, S. N. Dryepondt, and B. A. Pint, "High-Temperature Performance of UNS N07718 Processed by Additive Manufacturing," NACE Corros., 2014.

[163] R. R. Dehoff et al., "Site specific control of crystallographic grain orientation through electron beam additive manufacturing," Mater. Sci. Technol., vol. 31, no. 8, pp. 931-938, 2015.

[164] S. Liu and Y. C. Shin, "Additive manufacturing of Ti6Al4V alloy: A review," Mater. Des., vol. 164, p. 107552, 2019.

[165] J. J. Lewandowski and M. Seifi, "Metal Additive Manufacturing: A Review of Mechanical Properties," Annu. Rev. Mater. Res., vol. 46, no. 1, pp. 151-186, 2016.

[166] Q. Liu et al., "Microstructure and mechanical properties of LMD-SLM hybrid forming Ti6A14V alloy," Mater. Sci. Eng. A, vol. 660, pp. 24-33, 2016.

[167] T. M. Mower and M. J. Long, "Mechanical behavior of additive manufactured, powder-bed laserfused materials," Mater. Sci. Eng. A, vol. 651, pp. 198-213, 2016.

[168] C. Qiu, N. J. E. Adkins, and M. M. Attallah, "Microstructure and tensile properties of selectively laser-melted and of HIPed laser-melted Ti-6Al-4V," Mater. Sci. Eng. A, vol. 578, pp. 230-239, 2013.

[169] H. K. Rafi, N. V. Karthik, T. L. Starr, and B. E. Stucker, "Mechanical property evaluation of Ti6Al-4V parts made using Electron Beam Melting," 23rd Annu. Int. Solid Free. Fabr. Symp. - An Addit. Manuf. Conf., pp. 526-535, 2012.

[170] N. Hrabe and T. Quinn, "Effects of processing on microstructure and mechanical properties of a titanium alloy (Ti-6Al-4V) fabricated using electron beam melting (EBM), Part 2: Energy input, orientation, and location," Mater. Sci. Eng. A, vol. 573, pp. 271-277, 2013.

[171] H. Galarraga, D. A. Lados, R. R. Dehoff, M. M. Kirka, and P. Nandwana, "Effects of the microstructure and porosity on properties of Ti-6Al-4V ELI alloy fabricated by electron beam melting (EBM)," Addit. Manuf., vol. 10, pp. 47-57, 2016.

[172] T. Vilaro, C. Colin, and J. D. Bartout, "As-fabricated and heat-treated microstructures of the Ti6Al-4V alloy processed by selective laser melting," Metall. Mater. Trans. A Phys. Metall. Mater. Sci., vol. 42A, pp. 3190-3199, 2011.

[173] C. Romero, F. Yang, and L. Bolzoni, "Fatigue and fracture properties of Ti alloys from powderbased processes - A review," Int. J. Fatigue, vol. 117, pp. 407-419, 2018.

[174] S. Leuders et al., "On the mechanical behaviour of titanium alloy TiAl6V4 manufactured by selective laser melting: Fatigue resistance and crack growth performance," Int. J. Fatigue, vol. 48, pp. 300-307, 2013.

[175] X. W et al., "Additive manufacturing of strong and ductile Ti-6Al-4V by selective laser melting via in situ martensite decomposition," Acta Mater., vol. 85, pp. 74-84, 2015.

[176] D. MJ and D. SJ., Superalloys: a technical guide. Materials Park (OH): ASM International, 2002.

[177] Zuback JS and D. T., "Unpublished research." 2017.

[178] B. V, K. P, P. V, K. S, G. K, and S. R, "A review on powder bed fusion technology of metal additive manufacturing," in 4th International conference and exhibition on additive manufacturing technologies, 2014, pp. 1-2.

[179] Z. Sun, X. Tan, S. B. Tor, and W. Y. Yeong, "Selective laser melting of stainless steel 316L with low porosity and high build rates," Mater. Des., vol. 104, pp. 197-204, 2016.

[180] Z. Wang, T. A. Palmer, and A. M. Beese, "Effect of processing parameters on microstructure and tensile properties of austenitic stainless steel 304L made by directed energy deposition additive manufacturing," Acta Mater., vol. 110, pp. 226-235, 2016.

[181] R. L. Plaut, C. Herrera, D. M. Escriba, P. R. Rios, and A. F. Padilha, "A Short review on wrought austenitic stainless steels at high temperatures: processing, microstructure, properties and performance," Mater. Res., vol. 10, no. 4, pp. 453-460, 2007.

[182] R. G. Thomas and D. Yapp, "The Effect of Heat Treatment on Type 316 Stainless Steel Weld Metal," 1978.

[183] V. S. Raghunathan, V. Seetharaman, S. Venkadesan, and P. Rodriguez, "The influence of post 
weld heat treatments on the structure, composition and the amount of ferrite in type 316 stainless steel welds," Metall. Trans. A, vol. 10A, pp. 1683-1689, 1979.

[184] A. Etienne, B. Radiguet, N. J. Cunningham, G. R. Odette, R. Valiev, and P. Pareige, "Comparison of radiation-induced segregation in ultrafine-grained and conventional 316 austenitic stainless steels," Ultramicroscopy, vol. 111, pp. 659-663, 2011.

[185] T. R. Smith, J. D. Sugar, J. M. Schoenung, and C. S. Marchi, "Anomalous Annealing Response of Directed Energy Deposited Type 304L Austenitic Stainless Steel," JOM, vol. 70, no. 3, pp. 358363, 2018.

[186] K. Saeidi and F. Akhtar, "Subgrain-controlled grain growth in the laser-melted $316 \mathrm{~L}$ promoting strength at high temperatures," R. Soc. Open Sci., vol. 5, 2018.

[187] K. Zhang, S. Wang, W. Liu, and X. Shang, "Characterization of stainless steel parts by Laser Metal Deposition Shaping,” Mater. Des., vol. 55, pp. 104-119, 2014.

[188] M. Ziętala et al., "The microstructure, mechanical properties and corrosion resistance of $316 \mathrm{~L}$ stainless steel fabricated using laser engineered net shaping," Mater. Sci. Eng. A, vol. 677, pp. 110, 2016.

[189] M. Ma, Z. Wang, D. Wang, and X. Zeng, "Control of shape and performance for direct laser fabrication of precision large-scale metal parts with 316L Stainless Steel," Opt. Laser Technol., vol. 45, pp. 209-216, 2013.

[190] I. Tolosa, F. Garciandía, F. Zubiri, F. Zapirain, and A. Esnaola, "Study of mechanical properties of AISI 316 stainless steel processed by 'selective laser melting', following different manufacturing strategies,” Int. J. Adv. Manuf. Technol., vol. 51, pp. 639-647, 2010.

[191] A. Mertens et al., "Mechanical properties of alloy Ti-6Al-4V and of stainless steel 316L processed by selective laser melting: influence of out-of-equilibrium microstructures," Powder Metall., vol. 57, no. 3, pp. 184-189, 2014.

[192] A. Mertens, S. Reginster, Q. Contrepois, T. Dormal, O. Lemaire, and J. Lecomte-Beckers, "Microstructures and Mechanical Properties of Stainless Steel AISI 316L Processed by Selective Laser Melting," Mater. Sci. Forum, vol. 783-786, pp. 898-903, 2014.

[193] K. Abd-Elghany and D. L. Bourell, "Property evaluation of 304L stainless steel fabricated by selective laser melting," Rapid Prototyp. J., vol. 18, pp. 420-428, 2012.

[194] K. Guan, Z. Wang, M. Gao, X. Li, and X. Zeng, "Effects of processing parameters on tensile properties of selective laser melted 304 stainless steel," Mater. Des., vol. 50, pp. 581-586, 2013.

[195] B. Zhang, L. Dembinski, and C. Coddet, "The study of the laser parameters and environment variables effect on mechanical properties of high compact parts elaborated by selective laser melting 316L powder," Mater. Sci. Eng. A, vol. 584, pp. 21-31, 2013.

[196] A. Röttger, K. Geenen, M. Windmann, F. Binner, and W. Theisen, "Comparison of microstructure and mechanical properties of $316 \mathrm{~L}$ austenitic steel processed by selective laser melting with hotisostatic pressed and cast material," Mater. Sci. Eng. A, vol. 678, pp. 365-376, 2016.

[197] A. Riemer, S. Leuders, M. Thöne, H. A. Richard, T. Tröster, and T. Niendorf, "On the fatigue crack growth behavior in 316L stainless steel manufactured by selective laser melting," Eng. Fract. Mech., vol. 120, pp. 15-25, 2014.

[198] S. Afkhami, M. Dabiri, S. H. Alavi, T. Björk, and A. Salminen, "Fatigue characteristics of steels manufactured by selective laser melting," Int. J. Fatigue, vol. 122, pp. 72-83, 2019.

[199] A. B. Spierings, T. L. Starr, and K. Wegener, "Fatigue performance of additive manufactured metallic parts," Rapid Prototyp. J., vol. 19, no. 2, pp. 88-94, 2013.

[200] M. M, R. J, and F. D, Handbook of laser materials processing. Orlando, USA: Magnolia Publishing Inc, 2001.

[201] J. Li et al., "Microstructure and performance optimisation of stainless steel formed by laser additive manufacturing," Mater. Sci. Technol. (United Kingdom), vol. 32, no. 12, pp. 1223-1230, 2016. 
